\title{
Effective Ocular Delivery of Eplerenone Using Nanoengineered Lipid Carriers in Rabbit Model
}

\author{
Eman Abdelhakeem (D) \\ Mohamed El-nabarawi \\ Rehab Shamma \\ Department of Pharmaceutics and \\ Industrial Pharmacy, Faculty of Pharmacy, \\ Cairo University, Cairo, Egypt
}

Background: Eplerenone (Epl) is a selective mineralocorticoid-receptor antagonist used for chronic central serous chorioretinopathy treatment. Our goal was to enhance the corneal performance of Epl-loaded nanostructured lipid carriers (NLCs) through surface modification using different coating polymers.

Methods: Epl-loaded modified NLCs (Epl-loaded MNLCs) were prepared by coating the surface of Epl-loaded NLCs using different polymers, namely hyaluronic acid, chitosan oligosaccharide lactate, and hydrogenated collagen. A $3^{1} \times 4^{1}$ full factorial design was used to evaluate the effect of the surface modification on the properties of the prepared systems. Selected optimal Epl-loaded MNLCs were further evaluated for in vitro drug release, morphology, $\mathrm{pH}$, rheological properties, corneal mucoadhesion, irritation, and penetration.

Results: Epl-loaded MNLCs were successfully prepared with high drug-entrapment efficiency and nanosized particles with low size distribution. Transmission electron microscopy revealed nanosized spherical particles surrounded by a coating layer of the surface modifier. The $\mathrm{pH}$, refractive index, and viscosity results of the Epl-loaded MNLCs confirmed the ocular compatibility of the systems with no blurring of vision. The safety and ocular tolerance of the optimal MNLCs were confirmed using the hen's egg test on chorioallantoic membrane and by histopathological evaluation of rabbit eyes treated with the optimal systems. Confocal laser-scanning microscopy of corneal surfaces confirmed successful transcorneal permeation of the Epl-loaded MNLCs compared to the unmodified Epl-loaded NLCs, revealed by higher corneal fluorescence intensity at all time intervals.

Conclusion: Overall, the results confirmed the potential of Epl-loaded MNLCs as a direct approach for Epl ocular delivery.

Keywords: eplerenone, modified nanostructured lipid carriers, chronic central serous chorioretinopathy, surface modifiers

\section{Introduction}

Central serous chorioretinopathy (CSCR) is an intriguing ocular disease commonly causing visual impairment in the working-age population. CSCR is the fourth-most frequently encountered nonsurgical retinopathy after age-related macular degeneration, diabetic retinopathy, and retinal vein occlusion. ${ }^{1}$ It is characterized by acute or chronic neurosensory detachments of the retina in the posterior segment of the eye associated with or without detachments of the retinal pigment epithelium causing central visual disturbance and blurring. ${ }^{2,3}$ Examination of CSCR reveals subretinal fluid accumulation; however, the complex pathogenesis of CSCR is multifactorial and not fully understood.
Correspondence: Rehab Shamma Department of Pharmaceutics and Industrial Pharmacy, Faculty of Pharmacy, Cairo University, Cairo, Egypt Tel +20-0I II-930-1245

Email rehab.shamma@pharma.cu.edu.eg 
The use of mineralocorticoid antagonists as a potential treatment option has increased in several prospective and retrospective studies for CSCR treatment. ${ }^{4}$ Their action is due to the existence of an independent renin-angiotensinaldosterone system at the ocular level, with greater expression in retinal and uveal tissue and acting on the ocular vasculature, aqueous humor, and intraocular pressure control. ${ }^{5,6}$ Eplerenone (Epl) is a selective mineralocorticoid-receptor antagonist currently used for the treatment of CSCR. ${ }^{7}$ It is a class II drug according to the biopharmaceutical classification system, with low solubility and high permeability through biological membranes. ${ }^{8}$ Epl has the ability to act on neuroretinal cell types, ${ }^{9}$ modifying the a forementioned physiopathological processes. ${ }^{10-12}$

Topical formulations to treat intraocular diseases face obstacles, limiting their delivery, including precorneal loss factors (eg, tear dynamics, transient residence time in the cul-de-sac, and relative impermeability of the corneal epithelial membrane), resulting in poor bioavailability. ${ }^{13}$ In addition, the residence time of the drug on the corneal surface and drug penetration across the cornea still needs to be increased. ${ }^{14}$ Modifying viscosity has been adopted to prolong corneal residence time by applying hydrogels or in situ gelling systems. ${ }^{15}$ However, this has resulted in hindering permeation, leading to imperfect results. ${ }^{16}$ Therefore, the need for new strategies to improve drug bioavailability has increased. Lipid nanocarriers like nanostructured lipid carriers (NLCs) have shown excellent features for the ocular delivery of pharmaceuticals. ${ }^{16-18}$ Furthermore, modification of NLCs using surface modifiers (coating polymers) improves ocular drug bioavailability through prolonging corneal residence time. ${ }^{19-21}$ Surface modifiers are capable of enhancing the interaction between NLCs and ocular surface structures through hydrogen bonding and electrostatic and covalent bonding between the mucin layer covering the conjunctiva and/or the corneal surfaces of the eye and the applied surface modifier. ${ }^{22}$ In this article, different surface modifiers are used: hyaluronic acid (HA), COSL, and hydrogenated collagen.

HA is an anionic biodegradable biopolymer with interesting capacity for ocular delivery, since it is a major constituent of the vitreous humor, ${ }^{23}$ found throughout the retina, ${ }^{24}$ present in the extracellular matrix of many soft connective tissues, and is responsible for maintaining tissue-structure integrity, together with other structural macromolecules. ${ }^{25} \mathrm{HA}$ is known to be similar to mucin in terms of viscoelasticity, biophysical properties, and lubrication of the ocular surface. It has beneficial effects in providing long-lasting hydration and retention. The salt form of HA can easily cover the corneal epithelium. ${ }^{26,27}$

COSL is a cationic polymer of low molecular weight. ${ }^{28}$ Unlike chitosan, COSL has high aqueous solubility, making it suitable for ocular application. ${ }^{28}$ It has been reported that cationic polymers like the polycationic COSL have mucoadhesive properties due to their ability to develop electrostatic interactions with the negatively charged mucin, resulting in extended residence time on the ocular surface, along with the penetration-enhancement effect, leading to a significant improvement in ocular drug bioavailability. ${ }^{28}$

Collagen is one of the most useful biomaterials, with excellent biocompatibility, biodegradability, weak antigenicity, and high safety due to its biological characteristics. Collagen can be dispersed in aqueous media, forming a clear colloidal solution. Collagen-based nanoparticles have demonstrated excellent potential as a sustained-release formulation through both topical and oral usage. ${ }^{29-31}$

Previously, our team succeeded in preparing Eplloaded NLCs, with small particles $(134 \mathrm{~nm})$ and polydispersity index (PDI; 0.31) and high entrapment efficiency (EE; 76\%) and $\zeta$-potential (ZP; $-34 \mathrm{mV}^{32}$ This NLCs were used as a base (core) for further surface modification to enhance the ocular delivery of Epl. In this study, three goals were achieved. The first was to develop Epl-loaded modified NLCs (MNLCs) according to a $3^{1} \times 4^{1}$ full factorial design using Design-Expert software to study the outcome of design variables on formulation characteristics and select an optimal formula based on the desirability function. The second was extensive in vitro evaluation to confirm the safety of the optimal Epl-loaded MNLCs for ocular delivery. Third, the in vivo safety of the NLCs was evaluated using histopathology analysis and the Draize test, in addition to in vivo imaging using confocal laser microscopy to demonstrate the transcorneal permeation ability of the system through rabbit eyes. To our knowledge, ocular delivery of Epl for CSCR treatment has not been investigated in the literature.

\section{Methods}

Epl was obtained from Shenzhen Oriental Pharmaceutical. Imwitor $900 \mathrm{~K}$ (glyceryl monostearate) was purchased from Changwei Pharmaceutical Excipients Technology. Pluronic F127 and Miglyol 812N was purchased from BASF. Hydrogenated collagen and HA were obtained from Acros Organics. COSL and porcine mucin powder 
were obtained from Sigma-Aldrich. Ethanol and acetone were obtained from El-Nasr Pharmaceutical Chemicals. All other chemicals were of analytical grade.

\section{Preparation of Epl-Loaded MNLCs}

Epl-loaded MNLCs were prepared by emulsification-solvent evaporation using Miglyol $812 \mathrm{~N}$ as liquid lipid and glyceryl monostearate as solid lipid (2:1 w:w liquid lipid: solid lipid), as per the method adopted by Shamma et al. ${ }^{33}$ In brief, $25 \mathrm{mg}$ of Epl were dispersed in a weighted amount of Miglyol $812 \mathrm{~N}$, then added to a determined amount of molten glyceryl monostearate (kept at $80^{\circ} \mathrm{C}$ using a magnetic stirrer with a heating plate). Ethanolacetone $10 \mathrm{~mL}(1: 1 \mathrm{v}: \mathrm{v})$ was added to the molten lipids maintained at $80^{\circ} \mathrm{C}$ until complete dissolution in the organic phase. The organic phase was then added to 20 $\mathrm{mL}$ aqueous solution containing Pluronic F127 as surfactant $(0.43 \% \mathrm{w}: \mathrm{v})$ to form a primary oil-in-water emulsion under stirring at 1,000 rpm for 1 minute using a magnetic stirrer. The emulsion obtained was subsequently subjected to 3 minutes of sonication using a probe sonicator (VCX 750 ultrasonic processor) adjusted to $40 \mathrm{~W}$. The NLCs formed were stirred using a magnetic stirrer at $500 \mathrm{rpm}$ for 2 hours at room temperature to allow the organic solvent to evaporate and tEpl-loaded NLCs to form. ${ }^{33}$ Coating of the Epl-loaded NLCs was achieved using the surface modifiers (HA, COSL, and hydrogenated collagen). Weighted amounts of the modifiers were added in the dispersion and stirred at $300 \mathrm{rpm}$ for 10 minutes to form surface-modified Epl-loaded NLCs.

\section{In Vitro Characterization of Epl-Loaded MNLCs}

Particle Size, PDI, and ZP

Particle size (PS), PDI, and ZP were measured using dynamic light scattering using a Zetasizer Nano ZS (Malvern Instruments). Appropriate dilution before measurement was performed for each system to obtain suitable scattering intensity $(1 \mathrm{~mL}$ system to $10 \mathrm{~mL}$ deionized water). Each system was measured three times.

\section{Entrapment Efficiency}

The EE (w:w) of Epl in the Epl-loaded MNLCs was determined indirectly through measuring the concentration of free drug in the aqueous phase of the MNLC dispersion. MNLC dispersion $(1 \mathrm{~mL})$ was centrifuged using a cooling centrifuge at 22,000 rpm for 1 hour at $4^{\circ} \mathrm{C}$ (Sigma 3-30 $\mathrm{KS})$. The supernatant was separated and properly diluted with ethanol, and the unentrapped drug concentration was estimated spectrophotometrically at $241 \mathrm{~nm}$ (Shimadzu UV-1601 PC). EE\% was calculated:

$$
\text { The } \rightleftarrows E E \%=\frac{W \rightleftarrows \text { initial }- \text { Wfree }}{W \rightleftarrows \text { initial }} \times 100
$$

where: $\mathrm{W}$ initial is the total drug amount and $\mathrm{W}$ free the unentrapped drug amount.

\section{Rheological Measurement}

Rheological properties of the MNLCs were evaluated using cone-and-plate viscometry (Brookfield DVT-2). The temperature of the plate was fixed at $35^{\circ} \pm 0.1^{\circ} \mathrm{C}$ by connecting it to a thermostatic water bath. Samples $(0.5$ $\mathrm{mL}$ ) of each system were added to the plate. The rate of shear was increased gradually, viscosity determined from instrument readings, and the systems were subjected to a continuous change in the shear rate $\left(0.5-600 \mathrm{~s} \mathrm{~s}^{-1}\right){ }^{34}$

\section{Impact of Formulation Variables}

A $3^{1} \times 4^{1}$ full factorial design was employed for preparing Epl-loaded MLNCs using Design-Expert software version 7 (Stat-Ease). Two factors were evaluated in this design: the type of surface modifier, which was evaluated on three levels, and the second the concentration of surface modifier which was evaluated on four levels. As a result, 12 formulae were prepared and evaluated for the dependent variables: PS ( $\left.\mathrm{Y}_{1}\right)$, PDI $\left(\mathrm{Y}_{2}\right), \mathrm{ZP}\left(\mathrm{Y}_{3}\right), \mathrm{EE} \%\left(\mathrm{Y}_{4}\right)$, and viscosity $\left(\mathrm{Y}_{5}\right.$; Table 1). One-way ANOVA was performed to test the significance of each factor $(p<0.05)$ on the selected responses.

\section{Optimized Epl-Loaded MNLCs}

Design-Expert was employed to select the optimal Eplloaded MNLCs by applying the desirability function. Constraints were applied to obtain Epl-loaded MNLCs with the smallest PS, PDI $<0.5$, and highest EE, ZP, and viscosity.

\section{Further Investigations}

In Vitro Release of Epl from Epl-Loaded MNLCs in Simulated Lacrimal Fluid

The release of two selected Epl-loaded MNLC types (HAcoated MNLCs and COSL-coated MNLCs) was compared to the release of the unmodified one (Epl-loaded NLCs) in the same conditions, in order to ascertain the effect of the surface modifier on Epl release. The in vitro release study was carried out using dialysis-bag diffusion. Exactly $2 \mathrm{~mL}$ of the optimized MNLCs (equivalent to $2.5 \mathrm{mg} \mathrm{Epl)} \mathrm{was} \mathrm{put}$ into the dialysis bag (molecular weight cutoff 12,000- 
Table I Experimental Runs, Independent Variables, and Measured Responses of the $3^{1} \times 4^{1}$ Full Factorial Experimental Design of Eplloaded MNLCs

\begin{tabular}{|c|c|c|c|c|c|c|c|}
\hline $\begin{array}{l}\text { F (Sorted } \\
\text { by Standard } \\
\text { Order) }\end{array}$ & $\begin{array}{c}\text { Type of Surface } \\
\text { Modifier }\end{array}$ & $\begin{array}{l}\text { Concentration } \\
\text { of Surface } \\
\text { Modifier (\% w: } \\
\text { v) }\end{array}$ & $Y_{1}: P S(n m)$ & $\mathbf{Y}_{2}:$ PDI & $\begin{array}{l}Y_{3}: Z P \\
(\mathrm{mV})\end{array}$ & $\begin{array}{c}Y_{4}: \text { EE\% (\% } \\
\text { w:w) }\end{array}$ & $\begin{array}{c}Y_{5}: \text { Viscosity } \\
(c P) \text { at Shear } \\
\text { Rate }(20[1 / s])\end{array}$ \\
\hline MNLC-I & Hydrogenated collagen & 0.3 & $152.75 \pm 15.20$ & $0.333 \pm 0.01$ & $-28.1 \pm 0.42$ & $62.945 \pm 1.10$ & $39.24 \pm 0.1$ \\
\hline MNLC-2 & COSL & 0.3 & $282.25 \pm 32.31$ & $0.382 \pm 0.01$ & $+15.8 \pm 0.85$ & $69.948 \pm 0.77$ & $0 \pm 0$ \\
\hline MNLC-3 & Hyaluronic acid & 0.3 & $167 \pm 42.57$ & $0.416 \pm 0.16$ & $-44.25 \pm 1.63$ & $81.285 \pm 1.63$ & $186.39 \pm 0.32$ \\
\hline MNLC-4 & Hydrogenated collagen & 0.5 & $155.6 \pm 4.10$ & $0.362 \pm 0.07$ & $-24.1 \pm 0.57$ & $63.865 \pm 1.89$ & $39.24 \pm 0.56$ \\
\hline MNLC-5 & COSL & 0.5 & $236.15 \pm 26.38$ & $0.428 \pm 0.06$ & $+20.65 \pm 0.49$ & $70.583 \pm 9.08$ & $78.48 \pm 0.98$ \\
\hline MNLC-6 & Hyaluronic acid & 0.5 & $262.75 \pm 84.07$ & $0.449 \pm 0.03$ & $-48.1 \pm 1.13$ & $79.025 \pm 1.05$ & $333.54 \pm 0.15$ \\
\hline MNLC-7 & Hydrogenated collagen & 0.7 & $127.773 \pm 9.15$ & $0.38 I \pm 0.13$ & $-27.95 \pm 0.21$ & $67.28 I \pm 8.39$ & $49.05 \pm 0.17$ \\
\hline MNLC-8 & COSL & 0.7 & $222.95 \pm 11.10$ & $0.433 \pm 0.03$ & $+29.3 \pm 0.28$ & $70.26 \pm 0.08$ & $29.43 \pm 2.11$ \\
\hline MNLC-9 & Hyaluronic acid & 0.7 & $261.75 \pm 66.40$ & $0.434 \pm 0.04$ & $-53.2 \pm 1.13$ & $88.445 \pm 2.80$ & $824.04 \pm 1.65$ \\
\hline MNLC-IO & Hydrogenated collagen & 0.9 & $161.2 \pm 5.23$ & $0.393 \pm 0.04$ & $-30.944 \pm 0.93$ & $76.905 \pm 7.96$ & $39.24 \pm 1.24$ \\
\hline MNLC-II & COSL & 0.9 & $397.1 \pm 158.11$ & $0.428 \pm 0.16$ & $+46.35 \pm 1.77$ & $74.357 \pm 6.73$ & $9.8 I \pm 0.98$ \\
\hline MNLC- 12 & Hyaluronic acid & 0.9 & $277.45 \pm 36.56$ & $0.475 \pm 0.01$ & $-54.4 \pm 0.49$ & $90.775 \pm 3.57$ & $1373.4 \pm 0.47$ \\
\hline
\end{tabular}

Notes: Data presented as means \pm SD $(n=3)$. All systems contained $1.25 \mathrm{mg}$ Epl// mL.

Abbreviations: PS, particle size; PDI, polydispersity index; ZP, $\zeta$-potential; EE, entrapment efficiency.

$14,000 \mathrm{Da}$ ), then tightly closed at both ends. The filled dialysis bag was immersed in a bottle containing $100 \mathrm{~mL}$ simulated lacrimal fluid (pH7.4). ${ }^{35}$ The release was carried out using a thermostatic horizontal shaker (GFL Gesellschaft für Labortechnik) at $50 \mathrm{rpm}$ and $35^{\circ} \pm 0.5^{\circ} \mathrm{C} .{ }^{36}$ At determined time intervals $(0.25,0.5,1,1.5,2,4,6,8$, and 24hours), $3 \mathrm{~mL}$ aliquots were withdrawn and replaced with an equal volume of fresh medium, in order to keep a constant volume. ${ }^{37}$ Drug concentration was measured spectrophotometrically at $245 \mathrm{~nm}$ with ultraviolet spectroscopy (Shimadzu UV-1601 PC) using simulated lacrimal fluid as a blank. The release profiles were drawn by plotting the percentage of cumulative drug released at each time point versus time. Experiments were repeated three times, and results are expressed as mean $\pm \mathrm{SD}$. Data obtained from the release of the drug from different NLCs were statistically analyzed to test significance $(p<0.05)$.

\section{Mucoadhesion of the Selected Nanosystems}

The mucoadhesive properties of the two selected Eplloaded MNLCs were evaluated to get an insight on adhesion behavior upon contacting the corneal surface. Exactly $1 \mathrm{~mL}$ of each selected system was mixed with $0.1 \% \mathrm{w}$ : aqueous mucin dispersion (1:40) and incubated for 24 hours at $35^{\circ} \pm 2^{\circ} \mathrm{C}$. PS and $\mathrm{ZP}$ of the resulting dispersions were determined at three time points during the incubation $(6,12$, and 24 hours), using the same procedure mentioned earlier, and compared to those obtained for plain mucin aqueous dispersion. $^{38}$

\section{In Vitro Irritation Testing}

The possibility of irritation from the optimized MNLCs on the eye surface was studied in vitro using the hen's egg test on chorioallantoic membrane (HET-CAM). ${ }^{39}$ The two selected Epl-loaded MNLCs were applied directly onto egg CAM and observed for any alteration or change to the membrane, simulating their effect on the eye mucosal membrane when applied in vivo. ${ }^{39}$ The test involved three steps, as follows.

\section{Preparing the Eggs}

Fresh fertilized chicken eggs were incubated for 10 days at $37.5^{\circ} \pm 0.5^{\circ} \mathrm{C}$ and $66 \% \pm 5 \%$ relative humidity. During this period, rotation of the eggs was done three times per day to avoid the embryo sticking to one side. After 10 days, the eggs were candled to ensure the viability of the embryos and to mark the air space using a pencil (Figure 1I). Infertile eggs were discarded. Before use, the eggshell around the air space was removed using a dental rotary saw and scissors. After exposure of the inner membrane, it was sprayed with saline for moisturization. Just prior to use, the inner membrane was removed using forceps to expose the CAM and considered ready for application of the test substances.

\section{Application of Test Substances}

Three systems were tested, (the two selected Epl-loaded MNLCs and Epl aqueous suspension). For comparison, $10 \% \mathrm{NaOH}$ and saline were used as positive and negative controls, respectively. Exactly $0.3 \mathrm{~mL}$ of each tested 

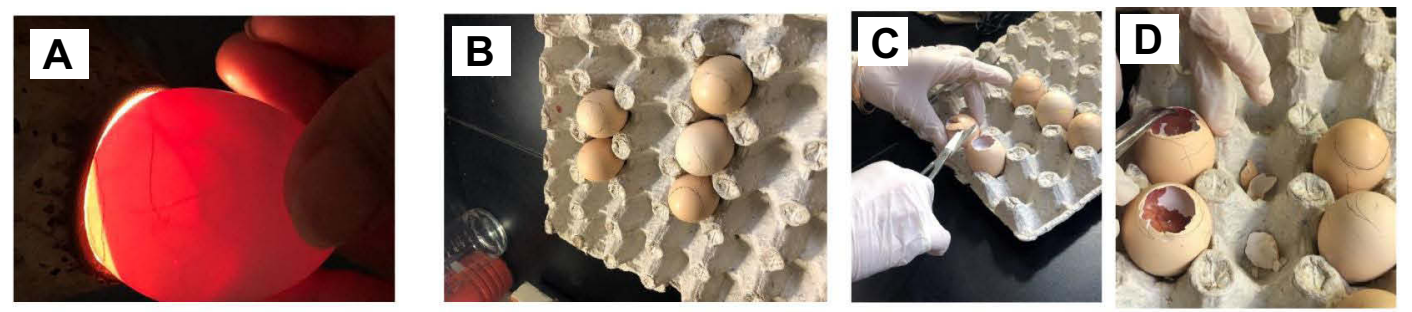

(I)
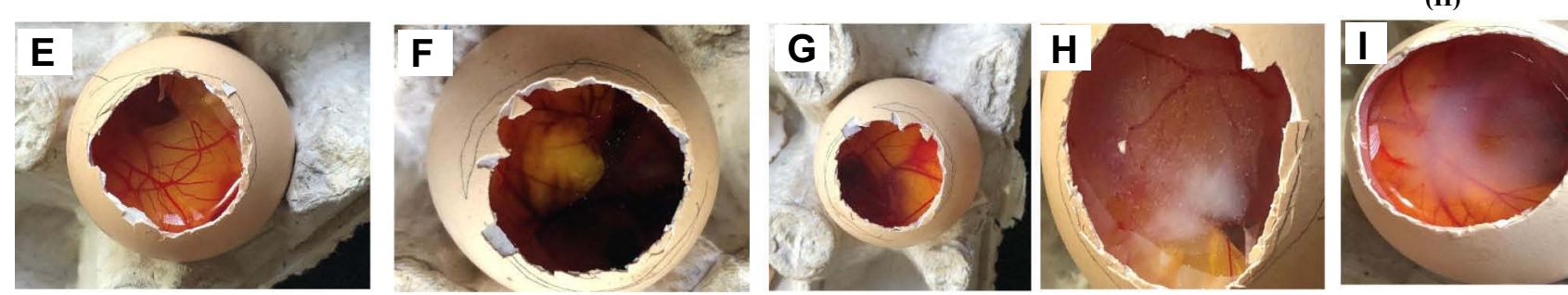

Figure I (I) Procedural steps for preparing the hen's egg on chorioallantoic membrane test (A-D). The egg was candled to check embryo viability (A) the air space marked (B), the external shell removed (C), and the inner membrane removed (D); (II) the observed responses to different systems application (E-H). Negative control (0.9\% $\mathrm{NaCl})(\mathbf{E})$; positive control $(10 \% \mathrm{NaOH})(\mathbf{F})$; Epl aqueous suspension (G); Epl- loaded COSL-MNLCs (H); Epl loaded HA-MNLCs (I).

system was applied directly to the exposed CAM, covering at least $50 \%$ of its surface for 5 minutes. ${ }^{40}$

\section{Visual Examination}

After application of the test substances, the CAM was visually observed for any vascular change, such as hemorrhage, hyperemia, lysis, extravascular coagulation, or intravascular thrombosis. ${ }^{41}$ Existence of any of these alterations reveals a possible tendency of the test compound to damage the eye mucosal membrane when applied in vivo. The CAM was photographed using a digital camera.

\section{$\mathrm{pH}$ values}

Measurement of $\mathrm{pH}$ values for the two selected systems was carried out with a Jenway $3505 \mathrm{pH}$ meter (Bibby Scientific). Exactly $1 \mathrm{~mL}$ of each of the selected systems was dispersed in $9 \mathrm{~mL}$ distilled water, then the $\mathrm{pH}$-meter electrode was immersed in the diluted dispersion and the value recorded. ${ }^{37}$ Measurement was carried out three times.

\section{Refractive Index}

The refractive index of the two selected systems was determined using a Hilger and Watts 46.17/63707 refractometer.

\section{Transmission Electron Microscopy}

TEM was used for assessment of particle morphology of the two selected systems. One drop of each system was appropriately diluted and adsorbed on a carbon-coated copper grid for 10 minutes at room temperature to allow some of the particles to adhere to collodion. Filter paper was used to draw off the excess dispersion, then, a drop of phosphotungstic acid dye (negative stain) was applied for 1 minute, the excess removed, and the sample air-dried then examined with TEM (JEOL JEM 1400). ${ }^{42}$

\section{Ocular Safety}

\section{Draize Test (Eye-Irritation Test)}

The two selected Epl-loaded MNLCs were evaluated in vivo for ocular irritation or damage by observing any opacity, redness, inflammation, or increased tear production upon application on the eyes of albino rabbits.

Three male albino rabbits $(2-2.5 \mathrm{~kg})$ were assigned for evaluating each system. Rabbits were housed in accordance with National Institutes of Health guidelines, and all procedures in the study conformed to the guidelines of the Research Ethics Committee for Experimental and Clinical Studies at the Faculty of Pharmacy, Cairo University (PI 2682). Both eyes were examined before testing to confirm the absence of any defects, the lower lid was gently pulled away from the eyeball to form a cup into which the assigned dose $(0.1 \mathrm{~mL})$ of each of the selected Epl-loaded MNLCs was instilled into the right eye, and $0.1 \mathrm{~mL}$ normal saline solution was instilled in the contralateral eye to serve as control. The eyes (cornea, iris, and conjunctiva) were examined for any signs of irritation and scored as suggested by Draize. ${ }^{43,44}$ An MNLC was considered nonirritant if it scored $0-3.9$, slightly irritant if 4-8.9, moderately irritant if $9-12.9$, and seriously irritant if $13-16 .{ }^{45}$ Additionally, in order to evaluate the multi-instillation effect, the assigned dose was given every hour for 6 hours (six instillations) and 
the eye structures examined for any irritation affecting the cornea (opacity), iris (inflammation), and conjunctiva (congestion, swelling, and discharge). ${ }^{46}$

\section{Histopathological Examination of Rabbit Eyes}

Thirty minutes after the last instillation, the rabbits were euthanized with an intravenous injection of sodium pentobarbital. Corneas receiving the selected MNLCs and control corneas receiving physiological saline were isolated, rinsed in physiological saline, and subsequently fixed in $10 \%$ formalin for 24 hours. Afterward, the isolated corneas were washed with tap water, then serial dilutions of alcohol (methyl, ethyl, and absolute ethyl) were used for dehydration. Specimens were cleared in xylene and embedded in paraffin at $56^{\circ} \mathrm{C}$ in an oven for 24 hours. With a sledge microtome, paraffin-beeswax tissue blocks were prepared for sectioning at $4 \mu \mathrm{m}$ thickness. The obtained tissue sections were collected on glass slides, deparaffinized, and stained with hematoxylin and eosin to be examined under light-electron microscopy. ${ }^{47}$

\section{Corneal Visualization}

\section{Fabrication of MNLCs Labeled with Rhodamine B}

The selected Epl-loaded MNLCs labeled with the fluorescent marker rhodamine $\mathrm{B}(\mathrm{RhB})$ were prepared by emulsification-solvent evaporation as previously mentioned, with a slight modification: $0.05 \% \mathrm{w}: \mathrm{v}$ RhB was added to the oil phase of the MNLCs. The rest of the procedure remained the same.

\section{Transcorneal Visualization}

Confocal laser-scanning microscopy (CLSM) was used to evaluate the ability of the tested formulations to boost drug corneal permeation, ${ }^{48}$ in addition to demonstrating the ocular mucoadhesion of uncoated NLCs and the two selected Eplloaded MNLCs. ${ }^{49}$ They were evaluated by imaging the intensity of RhB and its depth at the surface of the eye using CLSM (Carl Zeiss LSM 710, differential interference contrast, fluorescence, and bright field). The three groups of male albino rabbits were used for evaluating each system (uncoated NLCs and the two selected Epl-loaded MNLCs). Healthy animals free of clinically observable abnormalities were housed singly in standard cages in a light-controlled room ( 12 hours light and 12 hours dark cycles) at $20^{\circ}-24^{\circ} \mathrm{C}$ and $30 \%-75 \%$ relative humidity, with no restriction to food or water. On the day of the experiment, each group of rabbits received $0.1 \mathrm{~mL}$ of the tested formulations (uncoated NLCs, fluorescent Epl-loaded COSL-MNLCs, and Epl-loaded HA-
MNLCs) instilled in the eye using a micropipette. At predetermined time intervals after instillation $(1,2,4$, and 6 hours), the rabbits were euthanized with an intravenous injection of an overdose of sodium pentobarbital, given via a marginal ear vein, and the corneas removed, and fixed in physiological saline. The fluorescence intensity of $\mathrm{RhB}$ in the cornea was calculated after examination of the cornea using CLSM by taking mean intensity as the parameter, ${ }^{49}$ and confocal images were managed and fixed. ${ }^{50}$ Evaluation began from the outer corneal surface with the z-stack mode in the directions xy and xz. Surface by surface was imaged until complete $\mathrm{RhB}$ color disappearance. ${ }^{51,52}$ Image acquisition and analysis were processed using ZEN 2.3 software.

\section{Results and Discussion Preparation of Epl-Loaded MNLCs}

Epl-loaded NLCs were developed using emulsificationsolvent evaporation using solid and liquid lipids. The liquid oil used (Miglyol 812N) has been reported to be well tolerated by the eye, ${ }^{28,53,54}$ while the solid lipid, glyceryl monostearate, is a monoglyceride previously reported as safe for ocular drug delivery. ${ }^{55}$ In general, these lipids are already permitted by European and US regulatory authorities for topical applications, because they are well established in various dosage forms and have a status of generally being recognized as safe. ${ }^{56}$ Pluronic F127 was used as emulsifier, due to its ability to act as a thickening agent to increase formulation residence time on the ocular surface and to reduce physiological drug drainage. A nonionic emulsifier, Pluronic F127 is known to cause negligible or no ocular irritation. ${ }^{57}$

\section{Factorial Design Analysis}

A $3^{1} \times 4^{1}$ full factorial design was used and statistically analyzed using Design-Expert software. Each factor's levels were set based on preliminary trials. The model selected was two-factor interaction. Table 2 shows the independent variables, their respective levels, and the model summary statistics of the full factorial design used for optimization of Epl-loaded MNLCs. Adjusted and predicted $R^{2}$ were found to be within 0.2 difference, and this was attained in all responses.

\section{Effect of Formulation Variables on PS}

For ocular administration, PS is an important parameter to assure patient convenience and efficient and safe administration. Particles intended for ocular applications should not 
Table 2 Independent Variables, their Levels, and Summary Statistics of the $3^{1} \times 4^{1}$ Full Factorial Design Used for Optimization of Eplloaded MNLCs

\begin{tabular}{|c|c|c|c|c|c|c|}
\hline $\begin{array}{l}\text { Factors (independent } \\
\text { variables) }\end{array}$ & & & & & & \\
\hline Type of surface modifier & $\begin{array}{c}\text { Chitosan } \\
\text { oligosaccharide lactate }\end{array}$ & Hyaluronic & \multicolumn{4}{|c|}{ Hydrogenated collagen } \\
\hline $\begin{array}{l}\text { Concentration of surface } \\
\text { modifier (\% w:v) }\end{array}$ & 0.3 & 0.5 & 0.7 & \multicolumn{3}{|c|}{0.9} \\
\hline $\begin{array}{l}\text { Responses (dependent } \\
\text { variables) }\end{array}$ & $R^{2}$ & Adjusted $R^{2}$ & Predicted $R^{2}$ & Constraints & $\mathbf{P}$ & Adequate precision \\
\hline$Y_{1}: P S(n m)$ & 0.9985 & 0.9915 & 0.8459 & Minimize & 0.0069 & 41.924 \\
\hline$Y_{2}: P D I$ & 0.9185 & 0.8879 & 0.8243 & Less than 0.5 & 0.0001 & 16.330 \\
\hline$Y_{3}: Z P(m V)$ & 0.9703 & 0.9456 & 0.8164 & Maximize & 0.0002 & 19.364 \\
\hline $\mathrm{Y}_{4}: \mathrm{EE} \%$ & 0.9161 & 0.8846 & 0.8061 & Maximize & 0.0001 & 15.254 \\
\hline $\mathrm{Y}_{5:}$ Viscosity (cP) & 0.9756 & 0.9553 & 0.8493 & Maximize & 0.0001 & 19.891 \\
\hline
\end{tabular}

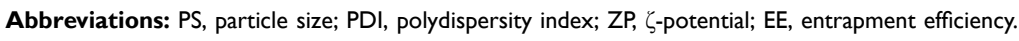

exceed $10 \mu \mathrm{m} .{ }^{58}$ Nanometric drug-delivery systems ensure less ocular irritation and better patient convenience, with much improvement in corneal penetration and retention time. $^{46}$

As presented in Table 1, the PS of the prepared Eplloaded MNLCs ranged from $127.77 \pm 9.15$ to 397.10 $\pm 158.11 \mathrm{~nm}$, which is acceptable for ocular administration. ${ }^{59}$ According to the ANOVA results (Table 2 ), the type of surface modifier and concentration had significant effects on the PS of the Epl-loaded MNLCs ( $p=0.0026$ and 0.0069 for effect of type and concentration of surface modifier, respectively).

The largest PS was observed in HA-coated Epl-loaded MNLCs, followed by COSL-coated ones, then hydrogenated collagen Epl-loaded MNLCs (Figure 2). This may be attributed to differences in viscositys which appear to increase in the same manner (as will be discussed later). Kamal et $\mathrm{al}^{60}$ reported that higher increase in PS during surface modification can be due to the effect of a surface modifier on the viscosity of the external aqueous phase. Similar results were also reported by Foucher et $\mathrm{al}^{61}$ for

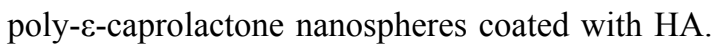

Increasing the concentration of the surface modifier significantly increased the PS of the prepared Epl-loaded MNLCs. This can be attributed to the increased crosslinking and interaction occurring at the surface of the NLCs with the surface modifier leading to observable PS enlargement. ${ }^{62,63}$ It is worth mentioning that the MNLCs had an extra transparent layer coating the outer surface (as would be confirmed later by TEM), its accounting for the increase in PS by increasing the concentration of the surface modifiers. ${ }^{64}$ These results are in agreement with Neslihan et al, ${ }^{65}$ where an increase in PS was observed with increased COSL concentration in the coating of ofloxacin-loaded ophthalmic NLCs.

\section{Effect of Formulation Variables on PDI}

PDI values represent the width of PS distributions, where smaller values are indicative of a stable monodispersed system in medium.

Table 1 shows the PDI values of the prepared Epl-loaded MNLCs, which ranged from $0.333 \pm 0.01$ to $0.475 \pm 0.01$. According to ANOVA results (Table 2), the type and concentration of surface modifier had significant effects on the PDI values of the prepared Epl-loaded MNLCs ( $p=0.0001$ and 0.0013 , respectively). The largest PDI value was observed upon using HA as a surface modifier, followed by COSL and finally hydrogenated collagen (Figure 2). These results conform with the PS results, where the PS of MNLCs increased in the same manner.

ANOVA results showed that increasing the concentration of surface modifier resulted in significantly higher PDI values. This may be due to particle bridging as, manifested by increasing the PS with increasing the concentration of surface modifier. This is in agreement with Jain et al. ${ }^{66}$

\section{Effect of Formulation Variables on ZP}

The high magnitude of absolute ZP provides an indication of better stability of the dispersion in an aqueous environment and ensures long-term storage without any settling. ${ }^{67}$ 


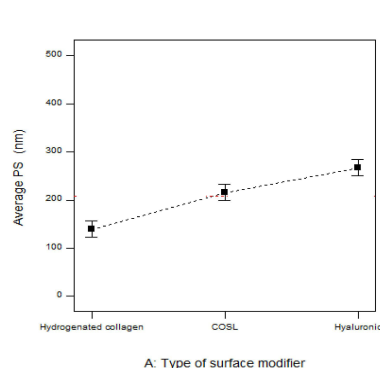

A
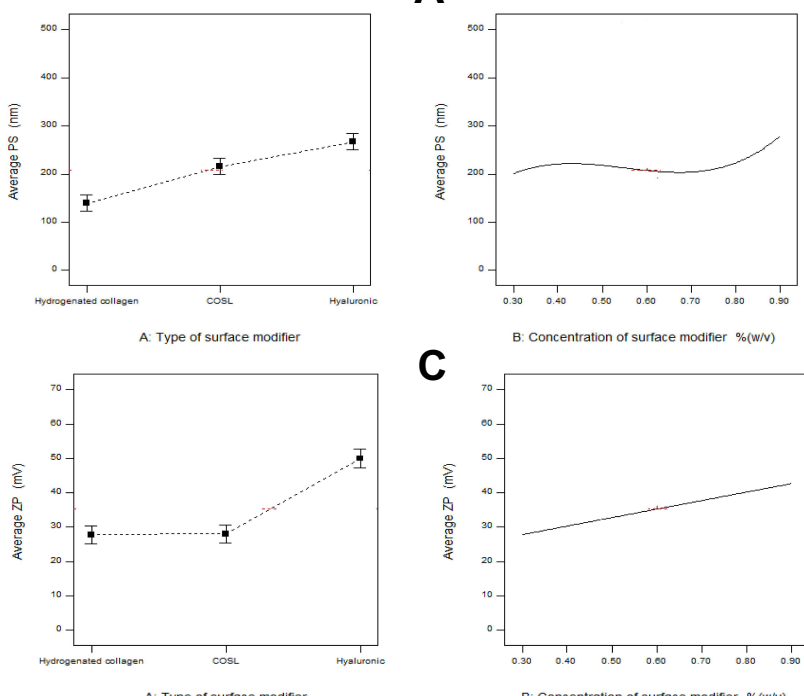

C

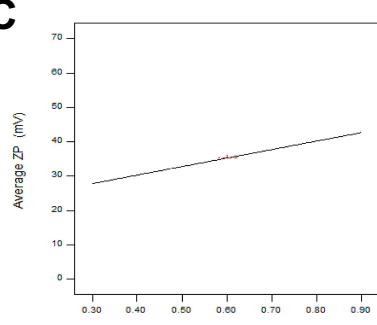

B: Concentration of surface modifier $\%(w / v)$

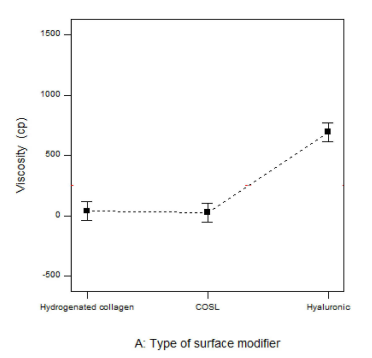

$\mathbf{E}$

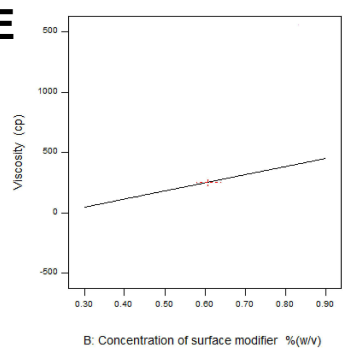

B
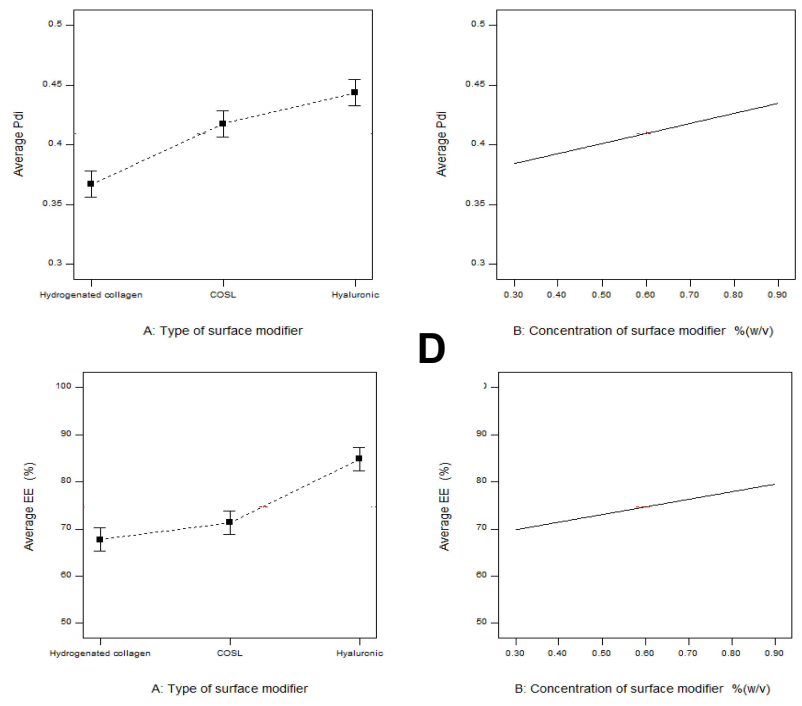

B: Concentration of surface modifer \%(W/v)

Figure 2 Line plots of significant effects of type of surface modifier and its concentration on (A) PS, (B) PDI, (C) ZP, (D) EE\%, and (E) viscosity.

Table 1 shows the ZP of the prepared Epl-loaded MNLCs, which ranged from $15.80 \pm 0.85$ to $54.40 \pm 0.49 \mathrm{mV}$ (absolute value). According to ANOVA results, type and concentration of the surface modifier had significant effects on ZP ( $p=0.0001$ and 0.0008 , respectively). Increasing the surface-modifier concentration led to a significant increase in ZP (absolute value). The largest absolute ZP values were observed with HA-coated systems (negatively charged), followed by COSL (positively charged) and hydrogenated collagen (negatively charged), which showed approximately the same absolute values (Figure 2). The change in ZP was concentration-dependent. Increasing surface-modifier concentration led to an increase in $\mathrm{ZP}$, in agreement with Zhang et al, ${ }^{54}$ who reported increased ZP upon increasing the concentration of Eudragit RS 100 (used for coating of NLCs).

Noteworthily, coating of Epl-loaded NLCs with only COSL resulted in the surface charge changing to positive (as manifested by positive $\mathrm{ZP}$ values) due to the adsorption of polycationic chitosan on the particle surface, ${ }^{68}$ whereas
HA increased the negative surface charge of Epl-loaded NLCs due to the polyanionic nature of the HA molecules. This high ZP enhanced the electrostatic stabilization of the system due to electrostatic repulsion among similarly charged MNLCs, providing a "stealth" characteristic that can mimic the prolonged precorneal retention of the NLCs, which might be due to the possible interaction of HA-coated NLCs with the hyaluronan receptors present on the corneal and conjunctival epithelial cells. ${ }^{62}$

\section{Effect of Formulation Variables on EE}

Epl EE in the prepared Epl-loaded MNLCs ranged from $62.94 \% \pm 1.10 \%$ to $90.77 \% \pm 3.57 \% \mathrm{w}$ : w (Table 1 ).

According to ANOVA results, the type and concentration of surface modifier had significant effects on the EE of Epl-loaded MNLCs ( $p=0.0001$ and 0.0035 , respectively, Table 2). The highest EE was observed with HA-coated Epl-loaded MNLCs, followed by COSL-coated ones then hydrogenated collagen Epl-loaded MNLCs. These results correlated well with the PS results, as previously 
discussed, where the highest PS was observed with HAcoated Epl-loaded MNLCs, followed by COSL-coated ones then hydrogenated collagen Epl-loaded MNLCs. EE of drugs from lipid nanocarriers is highly dependent upon interfacial area, surface charge, and nanoparticulate dimensions. ${ }^{69}$ Previous reports in the literature have shown that increasing the PS of nanoparticles leads to an increment in the EE of nanocarriers. ${ }^{70}$

Increasing the concentration of the surface modifiers led to a significant increment in EE. For COSL-coated ones, high EE might be attributed to the ionic interaction between the COSL and the anionic segment in the formulation, which efficiently prevents drug escape from the nanoparticles and imparts the MNLCs better stability. ${ }^{71}$ However, the HA in this product was in the form of sodium hyaluronate and collagen in the form of hydrogenated collagen. Positively charged ions from the monovalent alkali metal series, such as $\mathrm{Na}^{+}$and $\mathrm{H}^{+}$, act as counterions to anionic structure of NLCs (negatively charged), thus being absorbed on the surfacedominating negative sites and preventing drug escape and further increment in EE.

\section{Effect of Formulation Variables on Viscosity}

Table 1 shows the viscosity values of the prepared Eplloaded MNLCs. Each value represents the viscosity at a constant shear rate $20(1 / \mathrm{s})$ and ranges from $0 \pm 0$ to $1,373.4 \pm 0.47 \mathrm{cP}$. According to ANOVA results, the type and concentration of surface modifier had significant effects on viscosity ( $p=0.0001$ and 0.0011 , respectively). As illustrated in Figure 2, higher viscosity was observed with HA-coated systems, followed by COSL coated ones and finally hydrogenated collagen Epl-loaded MNLCs. This is due to capability of HA to produce high viscosity at low concentrations, owing to its high molecular weight and random-chain structure. ${ }^{72}$ Aqueous HA solutions have been reported to have non-Newtonian properties with high viscosity. ${ }^{73}$ The highest molecular weight reported for HA is $4,000 \mathrm{kDa},{ }^{74}$ followed by COSL $(3,000 \mathrm{kDa})^{56}$ and finally hydrogenated collagen $(300 \mathrm{kDa}),{ }^{75}$ as described by the product label. Increasing the concentration of the surface modifier led to a significant increment in viscosity, owing to increased polymer-chain entanglement. ${ }^{76}$

\section{Selection of the Optimal System}

The optimization process is directed to tailor independent formulation variables to produce a high-quality system with the optimum physicochemical properties. ${ }^{77}$ The desirability function was applied to select the optimum system. Desirability constraints for the optimum systems were minimizing PS, maximizing EE, maximizing ZP (absolute), maximizing viscosity, and achieving PDI $<0.5$. Two selections with desirability values near 1 were chosen as optimized systems (a negatively charged system with a desirability value of 0.937 and a positively charged one with desirability of 0.720 ). Furthermore, to confirm the efficacy of the model, the two systems were prepared, characterized, and compared with the predicted responses.

Negatively charged HA-coated Epl-loaded MNLCs (Epl-loaded HA-MNLCs) were prepared using 0.85\% w: v HA, and showed EE of $90.77 \% \pm 3.57 \%$, PS $255 \pm 36.55$ $\mathrm{nm}$, PDI $0.40 \pm 0.01, \mathrm{ZP}-54.2 \pm 0.494 \mathrm{mV}$, and viscosity $1,200 \pm 9.81$ cP. Positively charged COSL-coated Eplloaded MNLCs (Epl-loaded COSL-MNLCs) were prepared using $0.84 \% \mathrm{w}: \mathrm{v}$ COSL, showed EE of $70.11 \%$ $\pm 0.084 \%$, PS $285 \pm 5.03 \mathrm{~nm}$, PDI $0.42 \pm 0.15$, ZP 30 $\pm 0.28 \mathrm{mV}$, and viscosity of $40.24 \pm 7.12 \mathrm{cP}$.

As shown in Table 3, there was strong similarity between the observed and predicted values of the two selected systems, confirming the validity of the optimization process. Based on the aforementioned results, both Epl-loaded HA-MNLCs and Epl-loaded COSLMNLCs were promising candidates for further investigation.

\section{In Vitro Release in Simulated Lacrimal Fluid}

In vitro drug release provides an indication of the delivery system in vivo. ${ }^{36}$ Figure 3 shows the release profiles of the two selected systems (Epl-loadedEpl-loaded HA-MNLCs and Epl-loadedEpl-loaded COSL-MNLCs) over 24 hours compared to unmodified NLCs. The unmodified NLCs showed an initial burst effect in the first 2 hours, due to the diffusion of the surface-attached drug, followed by sustained drug release, due to the diffusion of the entrapped drug from inside the vesicles to the surrounding aqueous medium. ${ }^{78,79}$ The two selected modified systems showed superiority in sustained drug release when compared to the unmodified one, where only $66.264 \% \pm 2.081 \%$ and $75.937 \% \pm 0.118 \%$ Epl had been released from Epl-loadedEpl-loaded HAMNLCs and Epl-loadedEpl-loaded COSL-MNLCs, respectively, after 8 hours. Several studies have reported that chitosan coating leads to an improvement in drug loading, 
Table 3 Predicted Values of Responses for Optimized Systems (Epl-loaded HA-MNLCs and Epl-loaded COSL-MNLCs) Compared to Actual Values, along with Prediction Intervals

\begin{tabular}{|l|c|c|c|c|c|c|}
\hline & Validity Parameters & $\mathbf{Y}_{\mathbf{1}}: \mathbf{P S}(\mathbf{n m})$ & $\mathbf{Y}_{\mathbf{2}}: \mathbf{P D I}$ & $\mathbf{Y}_{\mathbf{3}}: \mathbf{Z P} \mathbf{( m V )}$ & $\mathbf{Y}_{\mathbf{4}}:$ EE (\%) & $\mathbf{Y}_{\mathbf{5}}:$ Viscosity (cP) \\
\hline Epl-loaded HA-MNLCs & Predicted value & 265.54 & 0.464 & -54.47 & 88.94 & 1190.78 \\
& $95 \%$ prediction interval & $240.72-290.36$ & $0.44-0.48$ & $48.76-60.18$ & $84.75-93.12$ & $1,025.4-1,356.16$ \\
& Actual values & $255 \pm 36.55$ & $0.40 \pm 0.01$ & $-54.2 \pm 0.494$ & $90.77 \pm 3.57$ & $1,200 \pm 9.81$ \\
\hline \multirow{2}{*}{ Epl-loaded COSL-MNLCs } & Predicted value & 318.92 & 0.437828 & 40 & 75.2155 & 38.0875 \\
& 95\% prediction interval & $294.37-343.48$ & $0.419-0.45$ & $34.46-45.53$ & $71.09-79.33$ & $36.78-40.03$ \\
& Actual values & $285 \pm 5.03$ & $0.42 \pm 0.15$ & $30 \pm 0.28$ & $70.11 \pm 0.08$ & $40.24 \pm 7.12$ \\
\hline
\end{tabular}

controlling drug release, mucoadhesion, enhancing cellular uptake, and targeting delivery. ${ }^{63} \mathrm{Li}$ et $\mathrm{al}^{71}$ reported that coating of NLCs with chitosan oligosaccharides and carboxymethyl chitosan showed prolonged release characteristics compared to uncoated NLCs. The prolonged-release profile in the Epl-loadedEpl-loaded HA-MNLCs due to HA coating increases the thickness of nanocarriers, which increases the distance of drug diffusion, hence the slow release. ${ }^{80}$ Moreover, the increased viscosity obtained by the addition of surface modifiers is thought to lessen NLC motion in the formulation, hence slower drug release. ${ }^{65}$ One way-ANOVA revealed a significant difference in Epl released in 24 hours $\left(\mathrm{Q}_{24}\right)$ between unmodified NLCs and the two selected MNLCs ( $p=0.001$ and 0.003 for Epl-loadedEpl-loaded HAMNLCs and Epl-loadedEpl-loaded COSL-MNLCs, respectively). $\mathrm{Q}_{24}$ was $99.481 \% \pm 3.219 \%$ for the unmodified NLCs, and $75.555 \% \pm 0.16 \%$ and $83.128 \% \pm 0.859 \%$ ) for Epl-
loadedEpl-loaded HA-MNLCs and Epl-loadedEpl-loaded COSL-MNLCs, respectively.

\section{Mucoadhesion}

Evaluation of mucoadhesive properties was critical in indicating the ocular bioavailability of the selected systems (EplloadedEpl-loaded HA-MNLCs and Epl-loadedEpl-loaded COSL-MNLCs) along with their corneal retention behavior. The PS and ZP of mucin mixed with the two selected MNLCs (1:40 v:v) were measured using 0.1 w:v mucin solution as a reference. The PS for the two selected systems underwent a gradual increase till the end of incubation (Figure 4A). On the other hand, ZP of Epl-loadedEpl-loaded COSL-MNLCs reduced to a negative charge after only 6 hours and continued to drop till approximately reaching the same negative charge as pure mucin at the end of incubation (Figure 4B). The increase in PS and decrease in ZP of Epl-

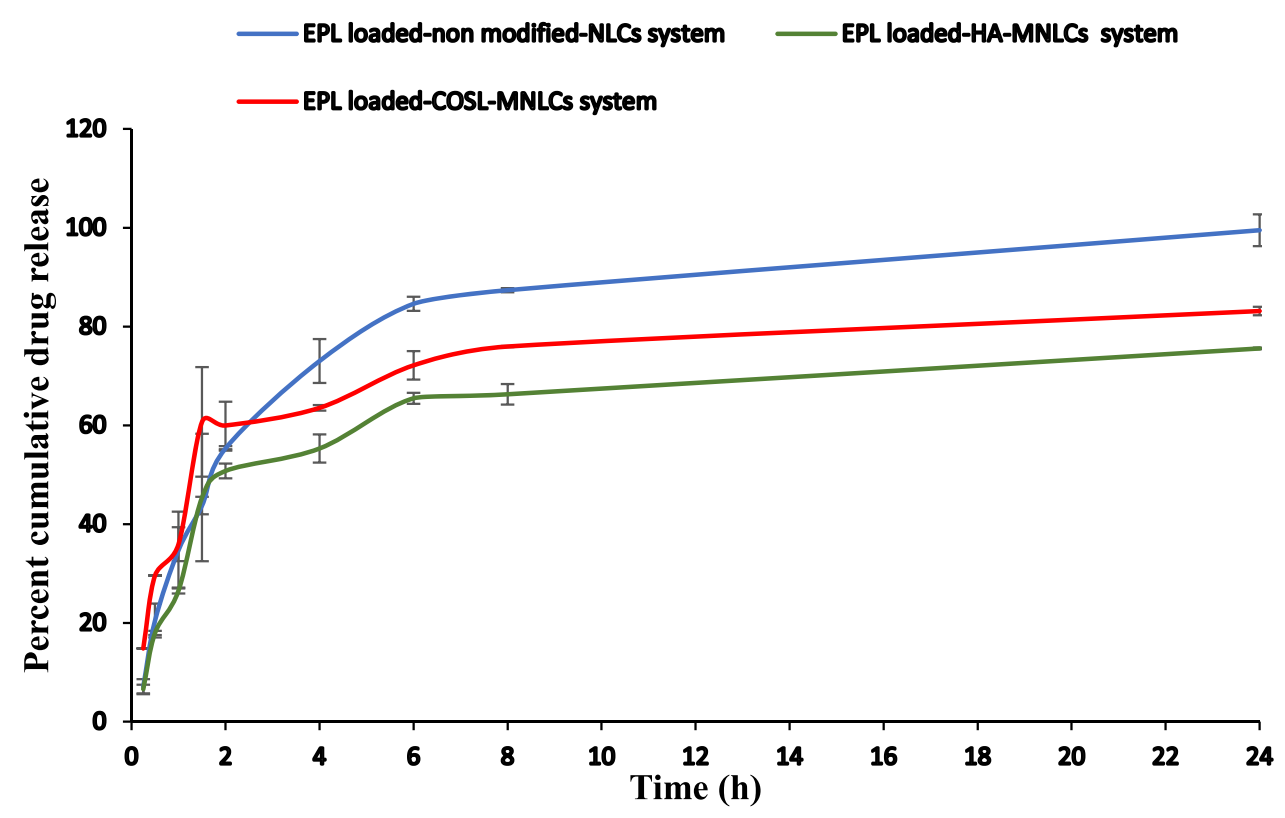

Figure 3 Cumulative release profile of Epl from loaded unmodified NLC system, Epl loaded HA-MNLCs and Epl loaded COSL-MNLCs. 


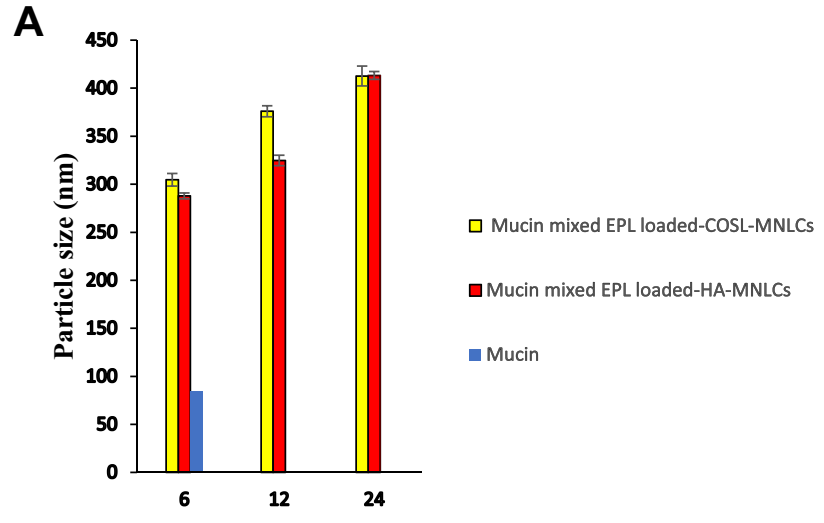

Time (h)

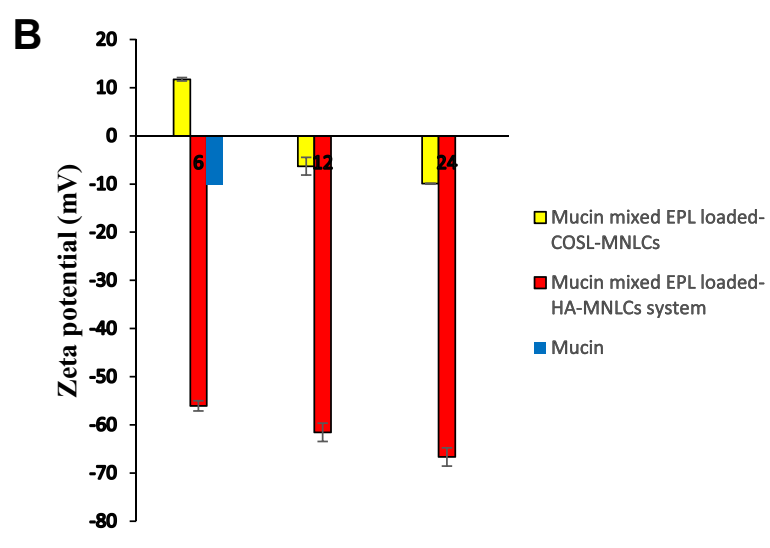

Time (h)

Figure 4 Mucoadhesion results: (A) PS measurements; (B) ZP measurements.

loadedEpl-loaded COSL-MNLCs could be attributed to electrostatic interaction between positively charged surface layer with negatively charged sialic groups of mucin as previously shown, ${ }^{81}$ which can lead to an increase in retention time on the mucosal surface. For Epl-loadedEpl-loaded HA-MNLCs, interaction occurred between the mucin and the HA due to the physical entanglements and hydrogen bonding between hydrophilic functional groups of HA, such as carbonyl and hydroxyl groups and mucin, ${ }^{76,82,83}$ which might be responsible for PS enlargement. On the other hand, ZP increased in the negative direction upon mixing Epl-loadedEpl-loaded HA-MNLCs with mucin. These negative values are attributed to HA because of its anionic nature, due to the presence of carboxylic groups. The mucin dispersion also presented a negative charge $(-10$ $\mathrm{mV}$ ) due to the oligosaccharide chains, which confer a negative charge through carboxyl and sulfate groups, the charge similar to previous studies $-10 \mathrm{mV}{ }^{84,85}$ As such, an increase in retention time on the corneal surface was expected for both systems, leading to an improvement in the efficacy of the ocular treatment.

\section{In Vitro Irritation Testing}

The HET-CAM test was used to detect possible irritation that may occur to ocular tissue upon application of the optimized systems (Epl-loadedEpl-loaded COSL-MNLCs and Eplloaded HA-MNLCs), predicting their potential safety. Perfect vascularization of CAM tissue (arteries, veins, and capillaries) clearly shows an inflammatory reaction in response to injury, so was used to mimic the eye's conjunctival tissue. ${ }^{86}$ As illustrated in Figure 1II, the positive control $(10 \% \mathrm{NaOH})$ was severely irritant, resulting in severe hyperemia and hemorrhage. On the other hand, $0.9 \% \mathrm{NaCl}$, used as the negative control, produced no irritant responses, as indicated by normal tissue vascularization (Figure 1II). The same results were obtained with the optimized systems and Epl suspension, where neither exhibited irritant effects on the CAM or any vascular damage. These findings confirm the safe and nonirritant characteristics of the optimized Eplloaded MNLCs as a potential platform to deliver Epl efficiently to ocular tissue.

\section{$\mathrm{pH}$ Values}

The $\mathrm{pH}$ values of the two selected systems were found to be $6.42 \pm 0$, and $7.39 \pm 0.12$ for Epl-loadedEpl-loaded COSLMNLCs and Epl-loadedEpl-loaded HA-MNLCs, respectively. The $\mathrm{pH}$ measurement confirmed the compatibility of these systems with the normal $\mathrm{pH}$ of tear fluid (7.4). ${ }^{87}$

\section{Refractive Index}

Refractive index values for ocular preparations are an important indicator of discomfort that may occur due to blurred vision after administration of ocular preparations. The light-refraction index for ophthalmic preparations should be $<1.5$ to prevent any discomfort in vision. ${ }^{88,89}$ The refractive index was found to be 1.28 and 1.37 for Epl-loadedEpl-loaded COSL-MNLCs and Epl-loadedEplloaded HA-MNLCs, respectively, within the acceptable range and indicating no effect on vision.

\section{Transmission Electron Microscopy}

Figure 5 shows the TEM images of Epl-loadedEpl-loaded HA-MNLCs (Figure 5A) and Epl-loadedEpl-loaded COSL-MNLCs (Figure 5B). The two selected MNLCs 

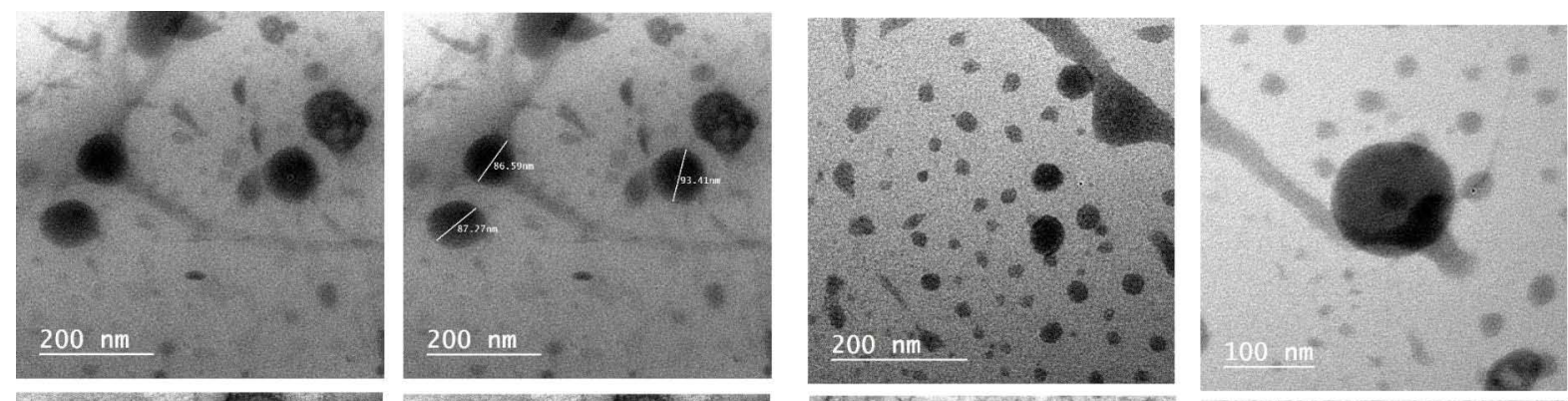

A
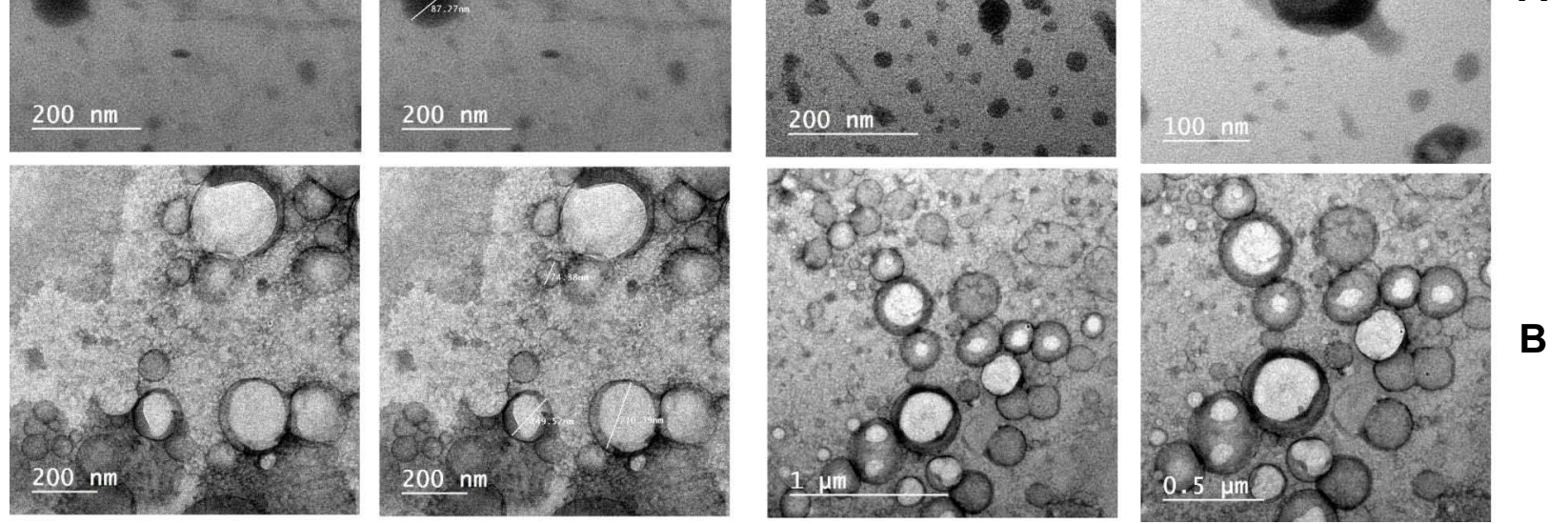

Figure 5 Transmission electron microscopy: (A) Epl loaded HA-MNLCs; (B) Epl loaded COSL-MNLCs.

were discrete spherical particles with a surface-adhering layer (surface modifier), as revealed by presence of a layer around each nanoparticle. In addition, the particles were separated from one another, assuring their stability.

\section{In Vivo Safety Assessment Draize Test (Eye Irritation)}

Unlike the other ingredients used in our study and to the best of our knowledge, this was the first use of Epl in an ocular formulation.

Initial ocular irritation testing is of critical importance, due to the eye's sensitive nature. Special attention should be paid to evaluating irritation and toxicity to avoid any damage to ocular tissue ${ }^{58,90}$ Rabbits are preferred for irritation tests, due to their large eyes with well-described anatomy and physiology, ease of handling, low cost, and availability. ${ }^{91}$ The Draize test revealed that the selected Epl-loaded MNLCs were nonirritant and safe for ophthalmic administration. Upon visual examination, corneas treated with Epl-loaded MNLCs did not show any sign of ocular irritation, inflammation, redness, increased tear production, or corneal edema over the saline solution that was used as a blank during the observation period, and thus were scored 0 according to the Draize scoring system. ${ }^{43}$ (Figure 6). These observations suggested high ocular tolerance and were further confirmed by histopathological examination.

\section{Histopathological Examination}

This revealed no histopathological alteration in the cornea (outer and inner lining of the epithelium and stroma in between Figure $7 a_{2}$ and $a_{3}$ ) iris (Figure $7 b_{2}$ and $b_{3}$ ), retina, choroid, or sclera (Figure $7 c_{2}$ and $c_{3}$ ) in the treated group when compared to the control (Figure $7 a_{1}-c_{1}$ ). The absence of any ocular irritation and intolerability suggests that the two selected systems were well tolerated and can be used safely for ocular application.

\section{Transcorneal Visualization}

The interaction of the two selected modified systems (EplloadedEpl-loaded HA-MNLCs, and Epl-loadedEpl-loaded COSL-MNLCs) with corneal epithelia was investigated by observing the corneal samples using CLSM after administration of the systems into rabbit eyes in vivo at determined time intervals $(1,2,4$, and 6 hours), where they were prelabeled with fluorescent marker molecules ofRhB to provide visual evidence of cellular location. CLSM is considered s quantitative analysis test for absolute marker penetration. ${ }^{48}$

Figure 8I shows corneal epithelia exposed to RhBlabeled unmodified NLCs and RhB-labeled MNLCs at different time intervals. CLSM images using selective green filters confirmed cell uptake for the two selected Epl-loaded MNLCs and the unmodified NLCs, where transfer of the fluorescent marker was promoted by formation of a complex between the nanoparticles and the 


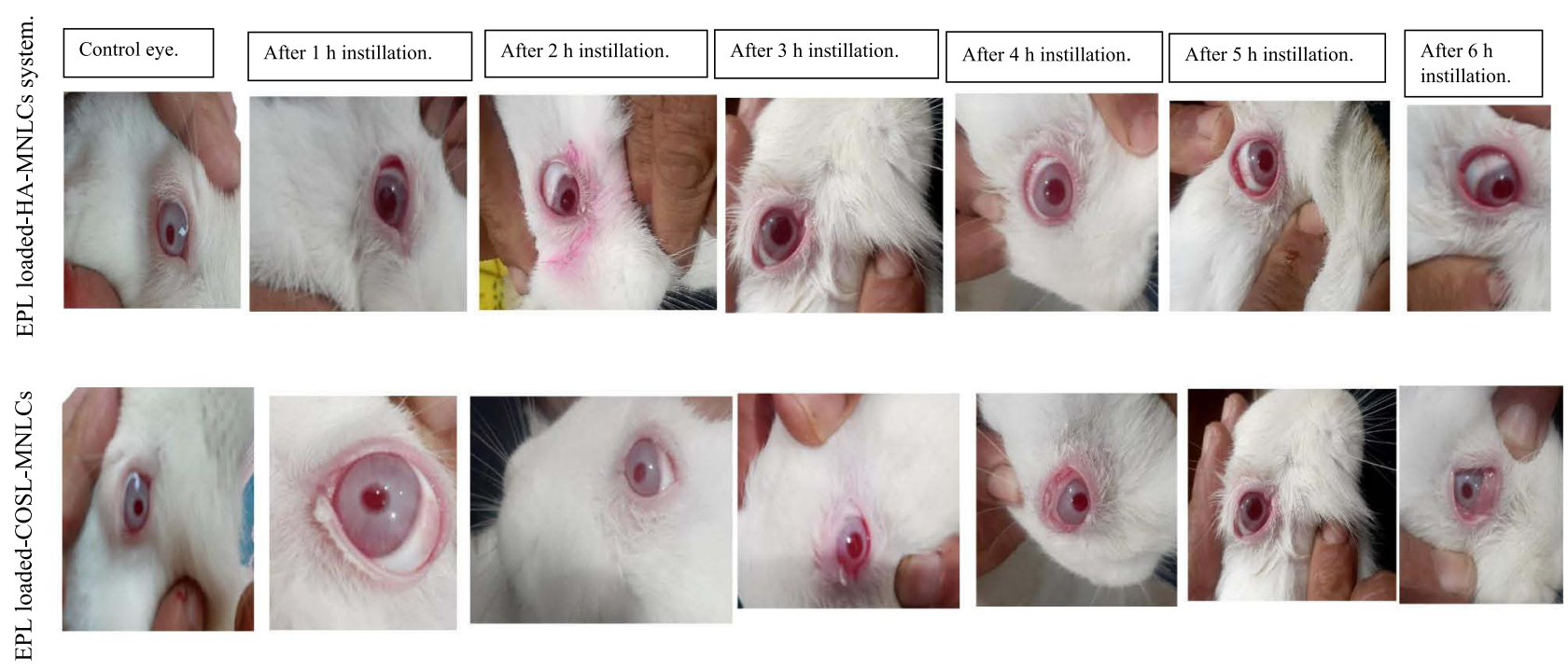

Figure 6 Photographs showing normal rabbit eyes after instillation of $0.1 \mathrm{~mL}$ physiological saline in a control eye, Epl loaded HA-MNLCs, and Epl loadedCOSL-MNLCs (instillation repeated every hour for 6 hours).

Normal untreated rabbit eye $\left(\mathrm{a}_{1}-\mathrm{c}_{1}\right)$.

$a_{1}$

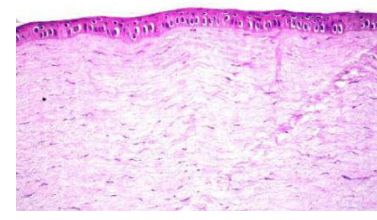

$\mathrm{b}_{1}$

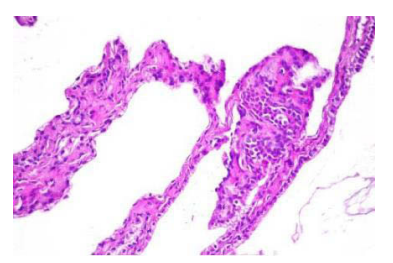

$\mathrm{c}_{1}$

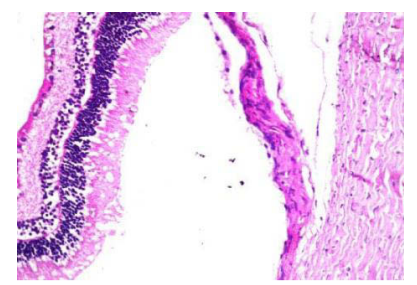

EPL loaded-HA-MNLCs system $\left(\mathrm{a}_{2}-\mathrm{c}_{2}\right)$.

$\mathrm{a}_{2}$

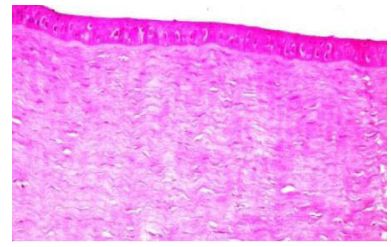

$\mathrm{b}_{2}$

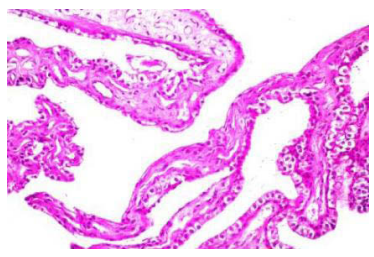

$\mathrm{c}_{2}$

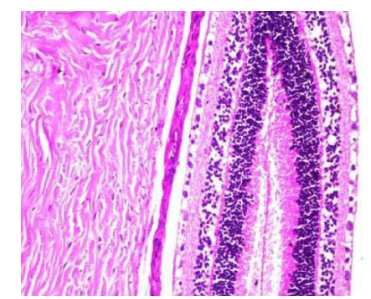

EPL loaded-COSL-MNLCs system ( $\left.a_{3}-c_{3}\right)$.

$a_{3}$

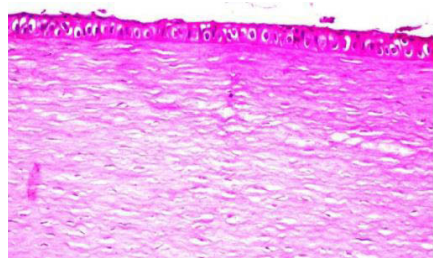

$\mathrm{b}_{3}$

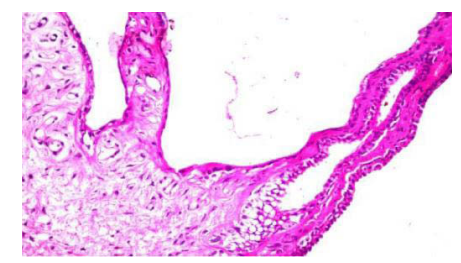

$\mathrm{C}_{3}$

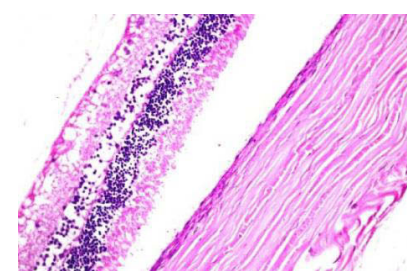

Figure 7 Histopathological stained sections (hematoxylin and eosin) of normal untreated rabbit eyes $\left(\mathrm{a}_{1}-\mathrm{c}_{1}\right)$ and rabbit eyes treated with Epl loaded HA-MNLCs ( $\left.\mathrm{a}_{2}-\mathrm{c}_{2}\right)$ and Epl loaded COSL-MNLCs $\left(\mathrm{a}_{3}-\mathrm{c}_{3}\right)$, where "a" represents the outer layer of the cornea, "b" the irisand ciliary process, and "c" the retina, choroid, and sclera at magnification $40 \times$.

biomembranes of the cornea, which led to staining of the corneal cells under investigation. ${ }^{92}$

Figure 8II shows the penetration of RhB (measure of depth in z-direction) from unmodified NLCs and the two selected MLNCs, as shown in an improvement in $\mathrm{RhB}$ penetration of $38 \mu \mathrm{m}$ and $22 \mu \mathrm{m}$ in HA- and COSLMNCLs, respectively, compared to $16 \mu \mathrm{m}$ in the unmodified system. Our finding was in agreement with a 
$1 \mathrm{~h}$

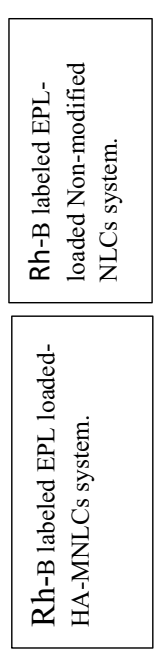

$2 \mathrm{~h}$
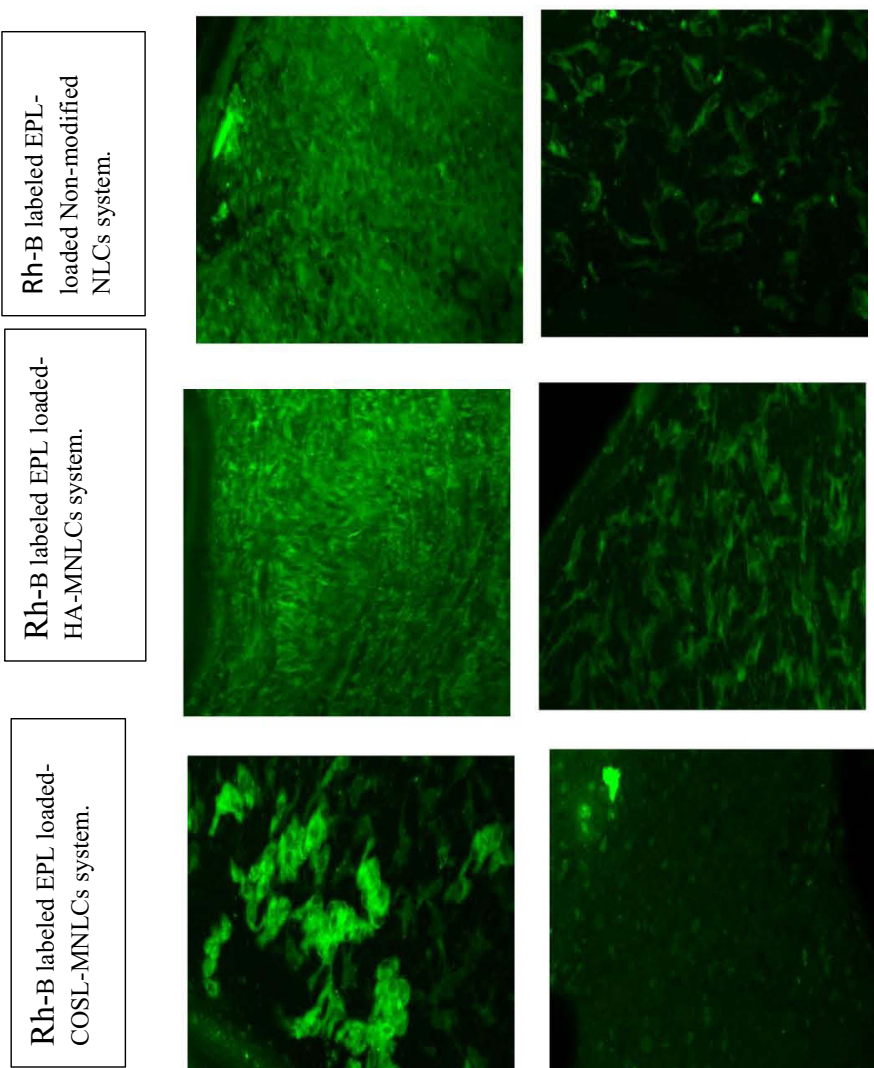
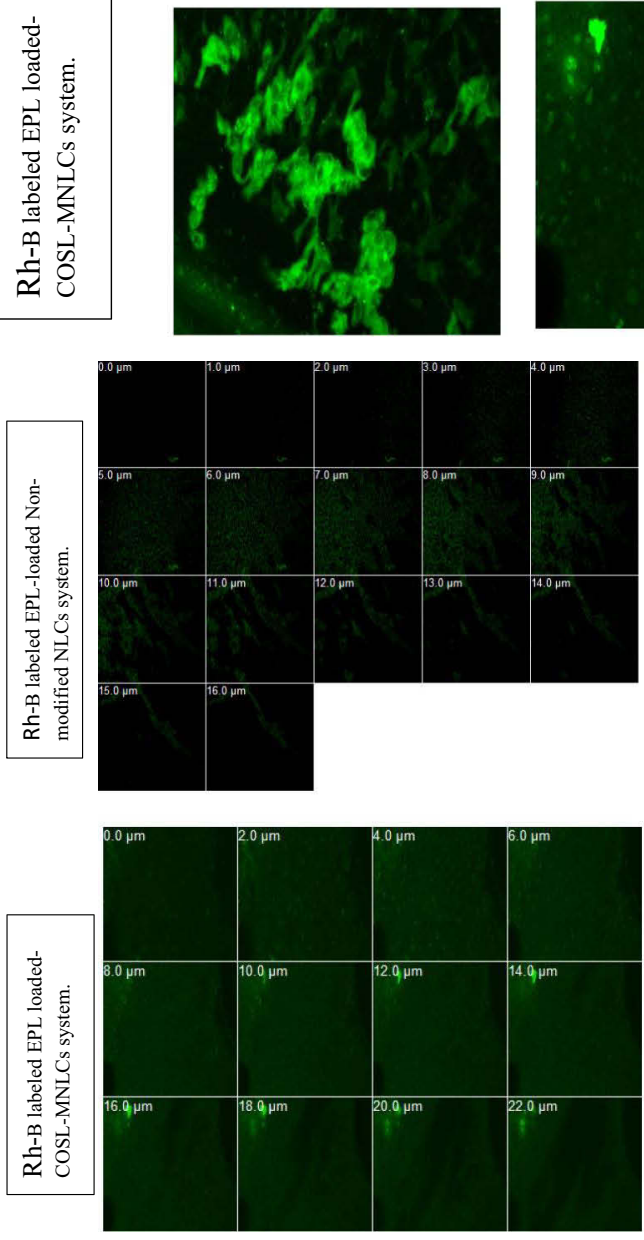

$4 \mathrm{~h}$
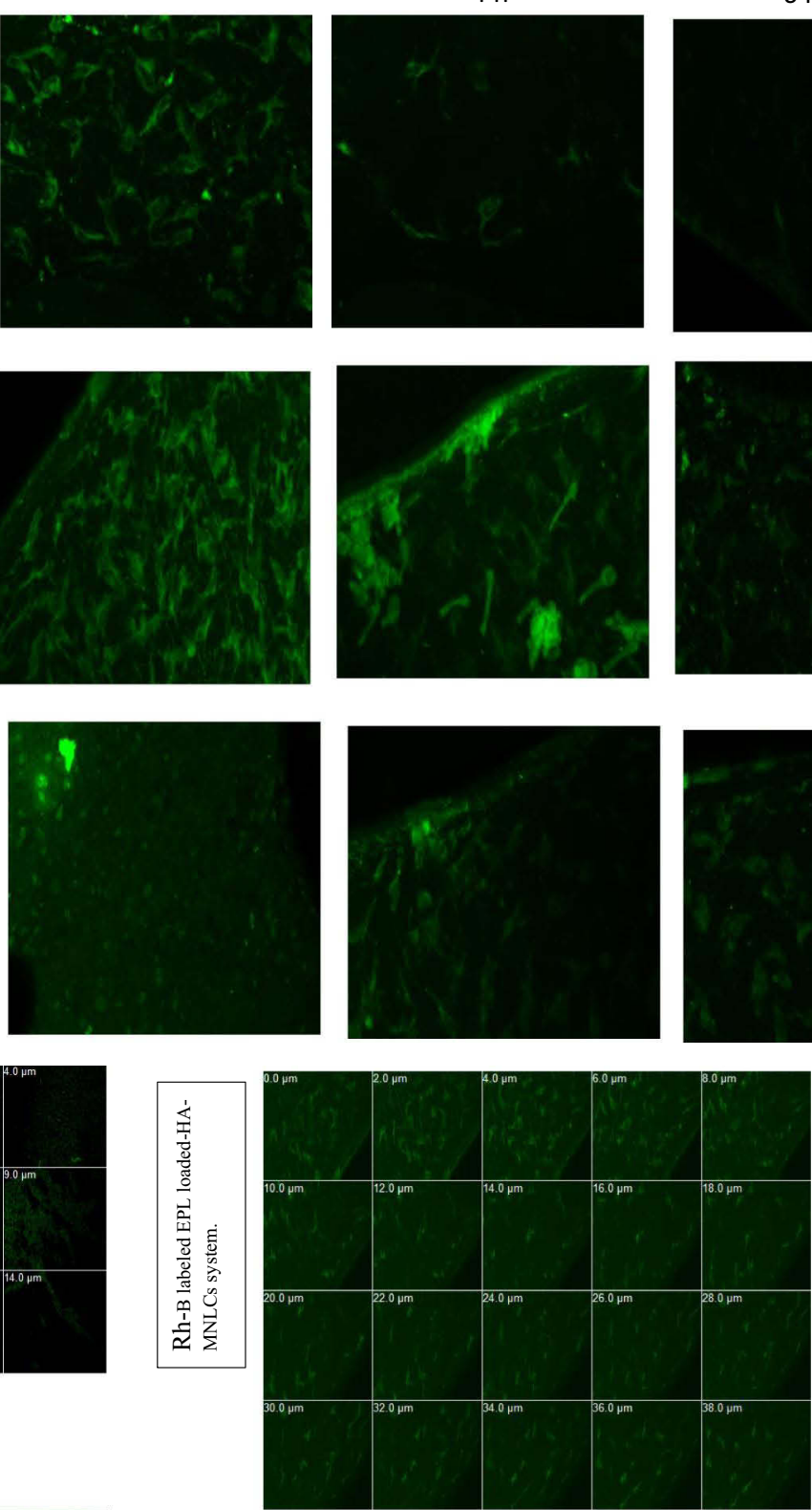

(II)

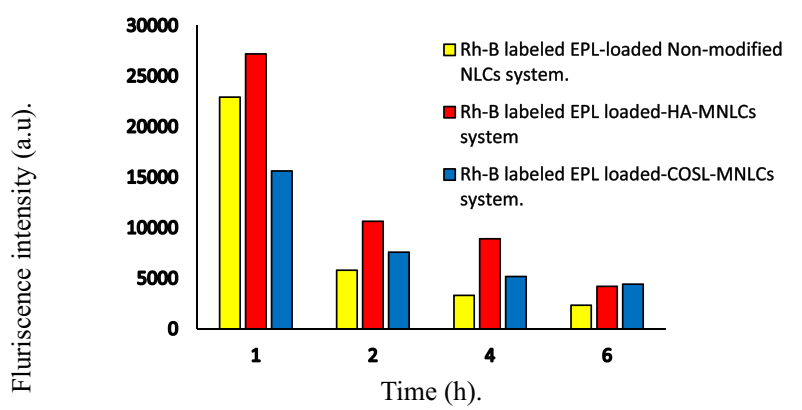

Figure 8 (I) Confocal laser-scanning microscopy of rabbit eyes at the corneal and scleral surfaces for RhB-labeled Epl-loaded unmodified NLCs, RhB-labeled Epl loaded HAMNLCs, and RhB-labeled Epl loaded COSL-MNLCs; (II) confocal laser-scanning microscopy of rabbit corneas showing the depth of RhB; (III) mean fluorescence intensity of RhB-labeled Epl-loaded unmodified NLCs, RhB labeled Epl loaded HA-MNLCs, and RhB-labeled Epl loaded COSL-MNLCs at the time points indicated on the bar graph. 
previously published work, where improved $\mathrm{RhB}$ penetration to a depth of $114 \mu \mathrm{m}$ from ocular proniosomal gel was achieved. ${ }^{93}$

Upon measuring the fluorescence intensity at the predetermined time intervals after administration, images of the cornea treated with RhB-labeled unmodified NLCs and RhBlabeled MLNCs showed significant fluorescence intensity beginning at 1 hour, as depicted in the bar plot (Figure 8III). As time increased, fluorescence intensity was found to drastically decrease for the unmodified NLCs, whereas the decrease in fluorescence intensity was only gradual for the modified ones. After 2 hours, results revealed 1.8- and 1.3fold higher fluorescence intensity in corneas treated with HA- and COSL-MNCLs, respectively, compared to cornea treated with unmodified NLCs. After 4 hours, there was 2.68and 1.56- fold higher fluorescence intensity in corneas treated with HA- and COSL-MNCLs, respectively, compared to corneas treated with unmodified NLCs. This higher retention of the two selected modified systems can be attributed to the presence of surface modifiers (HA and COSL), which helped in enhancing the retention in conjunctival regions and the surface of the eye. This result is in agreement with previous work utilizing cell surface-associated ocular mucin and chitosan oligosaccharide. ${ }^{94}$

This improved retention could be due to the presence of secreted mucin and cell surface-associated mucin, which is abundantly present across the conjunctival and corneal regions of the eye, perhaps resulting in retention of a more significant amount of the modified systems available across the surface of the eye, due to ionic interactions (as discussed previously). ${ }^{95,96}$ On the other hand, the unmodified NLCs had comparatively lower retention, which could be due to the impact of the clearance mechanisms of the eye, such as high tear-turnover rate and blinking, which otherwise would not significantly affect a mucoretentive system like the RhBlabeled MLNCs. Noteworthily, results revealed the superiority of HA-MNLCs over COSL-MNLCs, as revealed by higher corneal fluorescence intensity at all time intervals.

Based on the aforementioned results, we can reach the conclusion that NLC surface modification can enhance transcorneal Epl delivery and prolong precorneal retention time, thereby leading to higher ocular concentration.

\section{Conclusion}

In the present study, surface-modified Epl-loaded NLCs were designed and investigated for their in vitro characteristics, in vivo safety and tolerability, and in vivo transcorneal visualization using CLSM. Successful transcorneal delivery of the optimal Epl-loaded MNLCs was confirmed by higher fluorescence intensity for a longer time and greater depth in rabbit cornea than the unmodified NLCs. The final conclusions represent a direct approach for Epl ocular delivery. Furthermore, this could replace the necessity of oral use. Higher Epl concentration at the application site enhances efficiency and has fewer side effects.

\section{Acknowledgments}

Special thanks to Dr Hanaa Awad Elsamadony (researcher at the Animal Health Research Institute Poultry Department Virological Unit) for her continuous help and support, and special gratitude to Dr Heba (Nanotechnology and Advanced Material Central Lab, Regional Center for Food and Feed, Agriculture Research Center) for her help.

\section{Disclosure}

The authors report no conflicts of interest in this work.

\section{References}

1. Salehi M, Wenick AS, Law HA, Evans JR, Gehlbach P. Interventions for central serous chorioretinopathy: a network meta-analysis. Cochrane Database Syst Rev. 2015;12. doi:10.1002/14651858. CD011841.pub2

2. Gass DM. Atlas of Macular Diseases. St Louis: CV Mosby Co; 1987.

3. Wong KH, Lau KP, Chhablani J, Tao Y, Li Q, Wong IY. Central serous chorioretinopathy: what we have learnt so far. Acta Ophthalmol. 2016;94(4):321-325. doi:10.1111/aos.12779

4. Zhao M, Célérier I, Bousquet E, et al. Mineralocorticoid receptor is involved in rat and human ocular chorioretinopathy. J Clin Invest. 2012;122(7):2672-2679. doi:10.1172/JCI61427

5. Savaskan E, Löffler KU, Meier F, Müller-Spahn F, Flammer J, Meyer P. Immunohistochemical localization of angiotensin-converting enzyme, angiotensin II and AT1 receptor in human ocular tissues. Ophthalmic Res. 2004;36(6):312-320. doi:10.1159/000081633

6. Nakashima H, Suzuki H, Ohtsu H, et al. Angiotensin II regulates vascular and endothelial dysfunction: recent topics of angiotensin II type-1 receptor signaling in the vasculature. Curr Vasc Pharmacol. 2005. doi:10.2174/157016106775203126

7. Fusi-Rubiano W, Saedon H, Patel V, Yang YC. Oral medications for central serous chorioretinopathy: a literature review. Eye. 2020;34 (5):809-824. doi:10.1038/s41433-019-0568-y

8. Özdemir S, Çelik B, Sümer E, Acar ET, Üner M. Eplerenone nanoemulsions for treatment of hypertension. Part II: physical stability assessment and in vivo study. J Drug Deliv Sci Technol. 2018;45:287-295. doi:10.1016/j.jddst.2018.03.014

9. Zhao M, Valamanesh F, Celerier I, et al. The neuroretina is a novel mineralocorticoid target: aldosterone up-regulates ion and water channels in Müller glial cells. FASEB J. 2010;24(9):3405-3415. doi:10.1096/fj.09-154344

10. Yang D, Eliott D. Systemic mineralocorticoid antagonists in the treatment of central serous chorioretinopathy. Semin Ophthalmol. 2017;32(1):36-42. doi:10.1080/08820538.2016.1228418

11. Campos Polo R, Rubio Sánchez C, García Guisado DM, Díaz Luque MJ. Eplerenone, a new treatment for an old problem: retinitis pigmentosa with recalcitrant macular edema. Arch La Soc Española Oftalmol (English Ed. 2018;93(1):38-41. doi:10.1016/j. oftale.2017.05.012 
12. Chatziralli I, Vlachodimitropoulou A, Daoula C, et al. Eplerenone in the treatment of central serous chorioretinopathy: a review of the literature. Int J Retin Vitr. 2018;4(1):1-5. doi:10.1186/s40942-0180137-8

13. Bin-Jumah M, Gilani SJ, Jahangir MA, et al. Clarithromycin-loaded ocular chitosan nanoparticle: formulation, optimization, characterization, ocular irritation, and antimicrobial activity. Int J Nanomedicine. 2020;15:7861-7875. doi:10.2147/IJN.S269004

14. Tian B, Luo Q, Song S, et al. Novel surface-modified nanostructured lipid carriers with partially deacetylated water-soluble chitosan for efficient ocular delivery. J Pharm Sci. 2012;101(3):1040-1049. doi:10.1002/jps. 22813

15. Afzal M, Zafar A, Imam SS. Stimulus responsive ocular gentamycinferrying chitosan nanoparticles hydrogel: formulation optimization, ocular safety and antibacterial assessment. Int $J$ Nanomed. 2020;15:4717-4737. doi:10.2147/IJN.S254763

16. Iqbal MA, Md S, Sahni JK, Baboota S, Dang S, Ali J. Nanostructured lipid carriers system: recent advances in drug delivery. J Drug Target. 2012;20(10):813-830. doi:10.3109/1061186X.2012.716845

17. Liu R, Wang S, Sun L, et al. A novel cationic nanostructured lipid carrier for improvement of ocular bioavailability: design, optimization, in vitro and in vivo evaluation. J Drug Deliv Sci Technol. 2016;33:28-36. doi:10.1016/j.jddst.2016.03.009

18. Li X, Nie S-F, Kong J, Li N, Ju C-Y, Pan W-S. A controlled-release ocular delivery system for ibuprofen based on nanostructured lipid carriers. Int $J$ Pharm. 2008;363(1-2):177-182. doi:10.1016/j. ijpharm.2008.07.017

19. Felt O, Furrer P, Mayer JM, Plazonnet B, Buri P, Gurny R. Topical use of chitosan in ophthalmology: tolerance assessment and evaluation of precorneal retention. Int J Pharm. 1999;180(2):185-193. doi:10.1016/S0378-5173(99)00003-4

20. Chowdary KPR, Rao YS. Mucoadhesive microspheres for controlled drug delivery. Biol Pharm Bull. 2004;27(11):1717-1724. doi:10.1248/bpb.27.1717

21. Qi H, Chen W, Huang C, et al. Development of a poloxamer analogs/ carbopol-based in situ gelling and mucoadhesive ophthalmic delivery system for puerarin. Int $J$ Pharm. 2007;337(1-2):178-187. doi:10.1016/j.ijpharm.2006.12.038

22. Smart JD. The basics and underlying mechanisms of mucoadhesion. Adv Drug Deliv Rev. 2005;57(11):1556-1568. doi:10.1016/j. addr.2005.07.001

23. Bishop PN. Structural macromolecules and supramolecular organisation of the vitreous gel. Prog Retin Eye Res. 2000;19(3):323-344. doi:10.1016/S1350-9462(99)00016-6

24. Clark SJ, Keenan TDL, Fielder HL, et al. Mapping the differential distribution of glycosaminoglycans in the adult human retina, choroid, and sclera. Investig Ophthalmol Vis Sci. 2011;52(9):6511. doi:10.1167/iovs.11-7909

25. Xu X, Jha AK, Harrington DA, Farach-Carson MC, Jia X. Hyaluronic acid-based hydrogels: from a natural polysaccharide to complex networks. Soft Matter. 2012;8(12):3280. doi:10.1039/ c2sm06463d

26. Kashikar VS. Ophthalmic mucoadhesive polymers-A literature review. Int J Pharm Sci Rev Res. 2011;7:68-73.

27. Boddeda B, Ratna JV, Battu H. A review on mucoadhesive polymers in ophthalmics. Int J Pharm Sci Rev Res. 2014;24:237-45.

28. Luo Q, Zhao J, Zhang X, Pan W. Nanostructured lipid carrier (NLC) coated with chitosan oligosaccharides and its potential use in ocular drug delivery system. Int $J$ Pharm. 2011;403(1-2):185-191. doi:10.1016/j.ijpharm.2010.10.013

29. El-Samaligy MS, Rohdewald P. Reconstituted collagen nanoparticles, a novel drug carrier delivery system. J Pharm Pharmacol. 1983;35 (8):537-539. doi:10.1111/j.2042-7158.1983.tb04831.x

30. Kuwano M, Horibe Y, Kawashima Y. Effect of collagen cross-linking in collagen corneal shields on ocular drug delivery. $J$ Ocul Pharmacol Ther. 1997;13(1):31-40. doi:10.1089/jop.1997.13.31
31. Geggel HS, Friend J, Thoft RA. Collagen gel for ocular surface. Investig Ophthalmol Vis Sci. 1985;26(6):901-5.

32. Abd-elhakeem E, El-nabarawi M, Shamma R. Lipid-based nanoformulation platform for eplerenone oral delivery as a potential treatment of chronic central serous chorioretinopathy: in- vitro optimization and ex-vivo assessment. Drug Deliv. 2021;28(1):642-654. doi:10.1080/10717544.2021.1902023

33. Shamma RN, Aburahma MH, Aburahma MH. Follicular delivery of spironolactone via nanostructured lipid carriers for management of alopecia. Int J Nanomedicine. 2014;9:5449-5460. doi:10.2147/IJN.S73010

34. Tung IC. Rheological behavior of poloxamer 407 aqueous solutions during sol-gel and dehydration processes. Int J Pharm. 1994;107 (2):85-90. doi:10.1016/0378-5173(94)90445-6

35. Marques MRC, Loebenberg R, Almukainzi M. Simulated biological fluids with possible application in dissolution testing. Dissolution Technol. 2011;18(3):15-28. doi:10.14227/DT180311P15

36. Emad Eldeeb A, Salah S, Ghorab M. Proniosomal gel-derived niosomes: an approach to sustain and improve the ocular delivery of brimonidine tartrate; formulation, in-vitro characterization, and invivo pharmacodynamic study. Drug Deliv. 2019;26(1):509-521. doi:10.1080/10717544.2019.1609622

37. Fouda NH, Abdelrehim RT, Hegazy DA, Habib BA. Sustained ocular delivery of Dorzolamide-HCl via proniosomal gel formulation: invitro characterization, statistical optimization, and in-vivo pharmacodynamic evaluation in rabbits. Drug Deliv. 2018;25(1):1340-1349. doi:10.1080/10717544.2018.1477861

38. Younes NF, Abdel-Halim SA, Elassasy AI. Corneal targeted Sertaconazole nitrate loaded cubosomes: preparation, statistical optimization, in vitro characterization, ex vivo permeation and in vivo studies. Int J Pharm. 2018;553(1-2):386-397. doi:10.1016/j.ijpharm.2018.10.057

39. Elkasabgy NA. Ocular supersaturated self-nanoemulsifying drug delivery systems (S-SNEDDS) to enhance econazole nitrate bioavailability. Int $J$ Pharm. 2014;460(1-2):33-44. doi:10.1016/j. ijpharm.2013.10.044

40. Luepke NP, Kemper FH. The HET-CAM test: an alternative to the draize eye test. Food Chem Toxicol. 1986;24(6-7):495-496. doi:10.1016/0278-6915(86)90099-2

41. Alany RG, Rades T, Nicoll J, Tucker IG, Davies NM. W/O microemulsions for ocular delivery: evaluation of ocular irritation and precorneal retention. J Control Release. 2006;111(1-2):145-152. doi:10.1016/j.jconrel.2005.11.020

42. Badawi AA, El-laithy HM, Qidra RK, Mofty H, El M. Chitosan based nanocarriers for indomethacin ocular delivery. Arch Pharm Res. 2008;31(8):1040-1049. doi:10.1007/s12272-001-1266-6

43. Draize JH. Methods for the study of irritation and toxicity of substances applied topically to the skin and mucous membranes. $J$ Pharmacol Exp Ther. 1944;82:377-90.

44. Wilhelmus KR. The draize eye test. Surv Ophthalmol. 2001;45 (6):493-515. doi:10.1016/S0039-6257(01)00211-9

45. Liu Z, Nie S, Guo H, Pan W, Li J. Effects of transcutol P on the corneal permeability of drugs and evaluation of its ocular irritation of rabbit eyes. J Pharm Pharmacol. 2006. doi:10.1211/jpp.58.1.0006

46. Yousry C, Zikry PM, Salem HM, Basalious EB, El-Gazayerly ON. Integrated nanovesicular/self-nanoemulsifying system (INV/SNES) for enhanced dual ocular drug delivery: statistical optimization, in vitro and in vivo evaluation. Drug Deliv Transl Res. 2020;10(3):801814. doi:10.1007/s13346-020-00716-5

47. Warren B. Theory and practice of histological techniques. Pathology. 1996;28(4):381. doi:10.1016/s0031-3025(16)35146-7

48. Sayed S, Abdel-Moteleb M, Amin MM, Khowessah OM. Cubogel as potential platform for glaucoma management. Drug Deliv. 2021;28 (1):293-305. doi:10.1080/10717544.2021.1872740

49. Pai RV, Vavia PR. Chitosan oligosaccharide enhances binding of nanostructured lipid carriers to ocular mucins: effect on ocular disposition. Int $J$ Pharm. 2020;577:119095. doi:10.1016/j. ijpharm.2020.119095 
50. Abdelbary AA, Abd-Elsalam WH, Al-mahallawi AM. Fabrication of novel ultradeformable bilosomes for enhanced ocular delivery of terconazole: in vitro characterization, ex vivo permeation and in vivo safety assessment. Int $J$ Pharm. 2016;513(1-2):688-696. doi:10.1016/j.ijpharm.2016.10.006

51. Sayed S, Elsayed I, Ismail MM. Optimization of $\beta$-cyclodextrin consolidated micellar dispersion for promoting the transcorneal permeation of a practically insoluble drug. Int J Pharm. 2018;549(12):249-260. doi:10.1016/j.jpharm.2018.08.001

52. Elsayed I, Sayed S. Tailored nanostructured platforms for boosting transcorneal permeation: box-Behnken statistical optimization, comprehensive in vitro, ex vivo and in vivo characterization. Int $J$ Nanomedicine. 2017;12:7947-7962. doi:10.2147/IJN.S150366

53. Tian BC, Zhang WJ, Xu HM, et al. Further investigation of nanostructured lipid carriers as an ocular delivery system: in vivo transcorneal mechanism and in vitro release study. Colloids Surf B. 2013;102:251-256. doi:10.1016/j.colsurfb.2012.08.021

54. Zhang W, Li X, Ye T, et al. Nanostructured lipid carrier surface modified with Eudragit RS 100 and its potential ophthalmic functions. Int J Nanomedicine. 2014;9:4305-4315. doi:10.2147/IJN.S63414

55. Gasco MR, Saettone MF, Zara GP. Pharmaceutical compositions suitable for the treatment of ophthalmic diseases. 2006.

56. Sánchez-López E, Espina M, Doktorovova S, Souto EB, García ML. Lipid nanoparticles (SLN, NLC): overcoming the anatomical and physiological barriers of the eye - part II - Ocular drug-loaded lipid nanoparticles. Eur J Pharm Biopharm. 2017. doi:10.1016/j. ejpb.2016.10.013

57. Leonardi A, Bucolo C, Romano GL, et al. Influence of different surfactants on the technological properties and in vivo ocular tolerability of lipid nanoparticles. Int J Pharm. 2014;470(1-2):133-140. doi:10.1016/j.ijpharm.2014.04.061

58. Yousry C, Elkheshen SA, El-laithy HM, Essam T, Fahmy RH. Studying the influence of formulation and process variables on Vancomycin-loaded polymeric nanoparticles as potential carrier for enhanced ophthalmic delivery. Eur J Pharm Sci. 2017;100:142-154. doi:10.1016/j.ejps.2017.01.013

59. Janoria KG, Gunda S, Boddu SHS, Mitra AK. Novel approaches to retinal drug delivery. Expert Opin Drug Deliv. 2007;4(4):371-388. doi:10.1517/17425247.4.4.371

60. Kamal HI, El-leithy IS, Makky AA. Mucoadhesive nanoparticles as carrier systems for prolonged ocular delivery of gatifloxacin/prednisolone bitherapy. Molecular Pharmaceutics. 2010;(1):337-342.

61. Barbault-Foucher S, Gref R, Russo P, Guechot J, Bochot A. Design of poly- $\varepsilon$-caprolactone nanospheres coated with bioadhesive hyaluronic acid for ocular delivery. J Control Release. 2002;83(3):365-375. doi:10.1016/S0168-3659(02)00207-9

62. Kalam MA. Development of chitosan nanoparticles coated with hyaluronic acid for topical ocular delivery of dexamethasone. Int $J$ Biol Macromol. 2016. doi:10.1016/j.ijbiomac.2016.04.070

63. Zewail M, Nafee N, Helmy MW, Boraie N. Coated nanostructured lipid carriers targeting the joints - an effective and safe approach for the oral management of rheumatoid arthritis. Int $J$ Pharm. 2019;567:118447. doi:10.1016/j.ijpharm.2019.118447

64. Fahmy AM, Hassan M, El-Setouhy DA, Tayel SA, Al-Mahallawi AM. Statistical optimization of hyaluronic acid enriched ultradeformable elastosomes for ocular delivery of voriconazole via BoxBehnken design: in vitro characterization and in vivo evaluation. Drug Deliv. 2021;28(1):77-86. doi:10.1080/ 10717544.2020.1858997

65. Neslihan U, Gökçe EH, Bozbiyik DI, Eğrilmez S, Özer Ö, Ertan G. Preparation and in vitro-in vivo evaluation of ofloxacin loaded ophthalmic nano structured lipid carriers modified with chitosan oligosaccharide lactate for the treatment of bacterial keratitis. Eur $J$ Pharm Sci. 2014;63:204-215. doi:10.1016/j.ejps.2014.07.013
66. Jain A, Mishra SK, Vuddanda PR, Singh SK, Singh R, Singh S. Targeting of diacerein loaded lipid nanoparticles to intra-articular cartilage using chondroitin sulfate as homing carrier for treatment of osteoarthritis in rats. Nanomed Nanotechnol Biol Med. 2014;10(5): e1031-e1040. doi:10.1016/j.nano.2014.01.008

67. Pal SL. Nanoparticle: an overview of preparation and characterization. J Appl Pharm Sci. 2011;1(6):228-34.

68. Grant J, Allen C. Chitosan as a Biomaterial for Preparation of Depot-Based Delivery Systems. ACS Symposium Series. 2006.

69. Balguri SP, Adelli GR, Janga KY, Bhagav P, Majumdar S. Ocular disposition of ciprofloxacin from topical, PEGylated nanostructured lipid carriers: effect of molecular weight and density of poly (ethylene) glycol. Int J Pharm. 2017;529(1-2):32-43. doi:10.1016/j. ijpharm.2017.06.042

70. Jain B, Singh B, Katare OP, Vyas SP. Development and characterization of minoxidil-loaded liposomal system for delivery to pilosebaceous units. J Liposome Res. 2010;20(2):105-114. doi:10.3109/ 08982100903161449

71. Li J, Liu D, Tan G, Zhao Z, Yang X, Pan W. A comparative study on the efficiency of chitosan- $\mathrm{N}$-acetylcysteine, chitosan oligosaccharides or carboxymethyl chitosan surface modified nanostructured lipid carrier for ophthalmic delivery of curcumin. Carbohydr Polym. 2016;146:435-444. doi:10.1016/j.carbpol.2016.03.079

72. Ogston AG, Stanier JE. The dimensions of the particle of hyaluronic acid complex in synovial fluid. Biochem J. 1951;49(5):585-590. doi:10.1042/bj0490585

73. Daar E, King L, Nisbet A, Thorpe RB, Bradley DA. Viscosity changes in hyaluronic acid: irradiation and rheological studies. Appl Radiat Isot. 2010;68(4-5):746-750. doi:10.1016/j.apradiso.2009.10.022

74. Snetkov P, Zakharova K, Morozkina S, Olekhnovich R, Uspenskaya $M$. Hyaluronic acid: the influence of molecular weight and degradable properties of biopolymer. Polymers (Basel). 2020;12(8):1800. doi:10.3390/polym 12081800

75. Lee CH, Singla A, Lee Y. Biomedical applications of collagen. Int $J$ Pharm. 2001;221(1-2):1-22. doi:10.1016/S0378-5173(01)00691-3

76. Graça A, Gonçalves LM, Raposo S, Ribeiro HM, Marto J. Useful in vitro techniques to evaluate the mucoadhesive properties of hyaluronic acid-based ocular delivery systems. Pharmaceutics. 2018;10 (3):110. doi:10.3390/pharmaceutics 10030110

77. Al-Mahallawi AM, Khowessah OM, Shoukri RA. Nano-transfersomal ciprofloxacin loaded vesicles for non-invasive trans-tympanic ototopical delivery: in-vitro optimization, ex-vivo permeation studies, and in-vivo assessment. Int $J$ Pharm. 2014;472(1-2):304-314. doi:10.1016/j.ijpharm.2014.06.041

78. Pradhan M, Singh D, Murthy SN, Singh MR. Design, characterization and skin permeating potential of Fluocinolone acetonide loaded nanostructured lipid carriers for topical treatment of psoriasis. Steroids. 2015;101:56-63. doi:10.1016/j. steroids.2015.05.012

79. Youssef NAHA, Kassem AA, Farid RM, Ismail FA, EL-Massik MAE, Boraie NA. A novel nasal almotriptan loaded solid lipid nanoparticles in mucoadhesive in situ gel formulation for brain targeting: preparation, characterization and in vivo evaluation. Int $J$ Pharm. 2018;548(1):609-624. doi:10.1016/j.ijpharm.2018.07.014

80. Gao X, Zhang J, Xu Q, Huang Z, Wang Y, Shen Q. Hyaluronic acidcoated cationic nanostructured lipid carriers for oral vincristine sulfate delivery. Drug Dev Ind Pharm. 2017;43(4):661-667. doi:10.1080/03639045.2016.1275671

81. Bhatta RS, Chandasana H, Chhonker YS, et al. Mucoadhesive nanoparticles for prolonged ocular delivery of natamycin: in vitro and pharmacokinetics studies. Int J Pharm. 2012;432(1-2):105-112. doi:10.1016/j.ijpharm.2012.04.060

82. Leung SH, Robinson JR. The contribution of anionic polymer structural features to mucoadhesion. J Control Release. 1987;5(3):223-31. doi:10.1016/0168-3659(88)90021-1 
83. Zeng W, Li Q, Wan T, et al. Hyaluronic acid-coated niosomes facilitate tacrolimus ocular delivery: mucoadhesion, precorneal retention, aqueous humor pharmacokinetics, and transcorneal permeability. Colloids Surf B. 2016. doi:10.1016/j.colsurfb.2016.01.014

84. Fathalla ZMA, Khaled KA, Hussein AK, Alany RG, Vangala A. Formulation and corneal permeation of ketorolac tromethamineloaded chitosan nanoparticles. Drug Dev Ind Pharm. 2016;42 (4):514-524. doi:10.3109/03639045.2015.1081236

85. Menchicchi B, Fuenzalida JP, Bobbili KB, Hensel A, Swamy MJ, Goycoolea FM. Structure of Chitosan determines its interactions with mucin. Biomacromolecules. 2014;15(10):3550-3558. doi:10.1021/ bm5007954

86. Yousry C, Zikry PM, Basalious EB, El-Gazayerly ON. Self-nanoemulsifying system optimization for higher terconazole solubilization and non-irritant ocular administration. Adv Pharm Bull. 2020;10 (3):389-398. doi:10.34172/apb.2020.047

87. Achouri D, Alhanout K, Piccerelle P, Andrieu V. Recent advances in ocular drug delivery. Drug Dev Ind Pharm. 2013;39(11):1599-1617. doi:10.3109/03639045.2012.736515

88. Ammar HO, Salama HA, Ghorab M, Mahmoud AA. Nanoemulsion as a potential ophthalmic delivery system for dorzolamide hydrochloride. AAPS PharmSciTech. 2009;10(3). doi:10.1208/s12249-009-9268-4

89. Eldeeb AE, Salah S, Ghorab M. Formulation and evaluation of cubosomes drug delivery system for treatment of glaucoma: ex-vivo permeation and in-vivo pharmacodynamic study. J Drug Deliv Sci Technol. 2019;52:236-247. doi:10.1016/j.jddst.2019.04.036

90. Moosa RM, Choonara YE, Du Toit LC, et al. In vivo evaluation and in-depth pharmaceutical characterization of a rapidly dissolving solid ocular matrix for the topical delivery of timolol maleate in the rabbit eye model. Int J Pharm. 2014;466(1-2):296-306. doi:10.1016/j. ijpharm.2014.02.032
91. Roggeband R, York M, Pericoi M, Braun W. Eye irritation responses in rabbit and man after single applications of equal volumes of undiluted model liquid detergent products. Food Chem Toxicol. 2000;38(8):727-734. doi:10.1016/S0278-6915(00) 00057-0

92. Tian BC., Zhang WJ., Xu HM., et al. Further investigation of nanostructured lipid carriers as an ocular delivery system: In vivo transcorneal mechanism and in vitro release study. Colloids Surfaces B Biointerfaces. 2013 doi:10.1016/j.colsurfb.2012.08.021.

93. Sayed S, Abdelmoteleb M, Amin MM, Khowessah OM. Effect of formulation variables and gamma sterilization on transcorneal permeation and stability of proniosomal gels as ocular platforms for antiglaucomal drug. AAPS PharmSciTech. 2020;21(3). doi:10.1208/ s12249-020-1626-2

94. Pai RV, Monpara JD, Vavia PR. Exploring molecular dynamics simulation to predict binding with ocular mucin: an in silico approach for screening mucoadhesive materials for ocular retentive delivery systems. J Control Release. 2019;309:190-202. doi:10.1016/j. jconrel.2019.07.037

95. Bansil R, Turner BS. Mucin structure, aggregation, physiological functions and biomedical applications. Curr Opin Colloid Interface Sci. 2006;11(2-3):164-170. doi:10.1016/j.cocis.2005.11. 001

96. Grießinger J, Dünnhaupt S, Cattoz B, et al. Methods to determine the interactions of micro- and nanoparticles with mucus. Eur J Pharm Biopharm. 2015;96:464-476. doi:10.1016/j.ejpb.2015.01.005
International Journal of Nanomedicine

\section{Publish your work in this journal}

The International Journal of Nanomedicine is an international, peerreviewed journal focusing on the application of nanotechnology in diagnostics, therapeutics, and drug delivery systems throughout the biomedical field. This journal is indexed on PubMed Central, MedLine, CAS, SciSearch ${ }^{\circledR}$, Current Contents ${ }^{\mathbb{R}} /$ Clinical Medicine,

\section{Dovepress}

Journal Citation Reports/Science Edition, EMBase, Scopus and the Elsevier Bibliographic databases. The manuscript management system is completely online and includes a very quick and fair peer-review system, which is all easy to use. Visit http://www.dovepress.com/ testimonials.php to read real quotes from published authors. 